\title{
Backbone cyclization of analgesic conotoxin GeXIVA facilitates direct folding of the ribbon isomer
}

Received for publication, July 25, 2017 Published, Papers in Press, August 28, 2017, DOI 10.1074/jbc.M117.808386

\author{
Xiaosa $\mathrm{Wu}^{\ddagger}$, (1) Yen-Hua Huang ${ }^{\ddagger}$, (1) Quentin Kaas ${ }^{\ddagger}$, (1) Peta J. Harvey ${ }^{\ddagger}$, (1) Conan K. Wang ${ }^{\ddagger}$, Han-Shen Tae ${ }^{\S}$, \\ (D) David J. Adams ${ }^{\S}$, and (1) David J. Craik ${ }^{\neq 1}$ \\ From the ${ }^{\ddagger}$ Institute for Molecular Bioscience, University of Queensland, Brisbane, Queensland 4072, Australia and the $\$$ IIlawarra \\ Health and Medical Research Institute, University of Wollongong, Wollongong, New South Wales 2522, Australia
}

Edited by Norma Allewell

Conotoxin GeXIVA inhibits the $\alpha 9 \alpha 10$ nicotinic acetylcholine receptor ( $\mathrm{nAChR}$ ) and is analgesic in animal models of pain. $\alpha$-Conotoxins have four cysteines that can have three possible disulfide connectivities: globular $\left(\mathrm{Cys}^{\mathrm{I}}-\mathrm{Cys}^{\mathrm{III}}\right.$ and $\left.\mathrm{Cys}^{\mathrm{II}}-\mathrm{Cys}^{\mathrm{IV}}\right)$, ribbon (Cys ${ }^{\mathrm{I}}-\mathrm{Cys}^{\mathrm{IV}}$ and $\left.\mathrm{Cys}^{\mathrm{II}}-\mathrm{Cys}{ }^{\mathrm{III}}\right)$, or bead $\left(\mathrm{Cys}^{\mathrm{I}}-\mathrm{Cys}{ }^{\mathrm{II}}\right.$ and Cys ${ }^{\mathrm{II}}$-Cys $\left.{ }^{\mathrm{IV}}\right)$. Native $\alpha$-conotoxins preferably adopt the globular connectivity, and previous studies of $\alpha$-conotoxins have focused on the globular isomers as the ribbon and bead isomers typically have lower potency at nAChRs than the globular form. A recent report showed that the bead and ribbon isomers of GeXIVA are more potent than the globular isomer, with low nanomolar half-maximal inhibitory concentrations $\left(\mathrm{IC}_{50}\right)$. Despite this high potency, the therapeutic potential of GeXIVA is limited, because like most peptides, it is susceptible to proteolytic degradation and is challenging to synthesize in high yield. Here we used backbone cyclization as a strategy to improve the folding yield as well as increase the serum stability of ribbon GeXIVA while preserving activity at the $\alpha 9 \alpha 10$ nAChR. Specifically, cyclization of ribbon GeXIVA with a two-residue linker maintained the biological activity at the human $\alpha 9 \alpha 10 \mathrm{nAChR}$ and improved stability in human serum. Short linkers led to selective formation of the ribbon disulfide isomer without requiring orthogonal protection. Overall, this study highlights the value of backbone cyclization in directing folding, improving yields, and stabilizing conotoxins with therapeutic potential.

Acetylcholine receptors are present in the nervous system and at neuromuscular junctions and are defined as either muscarinic acetylcholine receptors or nicotinic acetylcholine receptors $(\mathrm{nAChRs})^{2}(1,2)$. Neuronal nAChR subtypes are homo- or heteropentamers formed by the combination of $\alpha(\alpha 2-\alpha 10)$ and $\beta(\beta 2-\beta 4)$ subunits. These neuronal nAChR subtypes are involved in a range of conditions and diseases,

This work was supported by Australian Research Council Grant DP150103990. The authors declare that they have no conflicts of interest with the contents of this article.

${ }^{1}$ Australian Research Council Australian Laureate Fellow supported by Grant FL150100146. To whom correspondence should be addressed. Tel.: 61-733462019; Fax: 61-7-33462101; E-mail: d.craik@imb.uq.edu.au.

${ }^{2}$ The abbreviations used are: $\mathrm{AAChR}$, nicotinic acetylcholine receptor; ACh, acetylcholine; RMSD, root-mean-square deviation; $\mathrm{Fmoc}, \mathrm{N}$-(9-fluorenyl)methoxycarbonyl; BPTI, bovine pancreatic trypsin inhibitor; RP, reversed-phase; BAPTA-AM, 1,2-bis(o-aminophenoxy)ethane- $N, N, N^{\prime}, N^{\prime}$-tetraacetic acid acetoxymethyl ester. including neuropathic pain, nicotine addiction, schizophrenia, Parkinson's disease, and Alzheimer's disease $(3,4)$.

Conotoxins are disulfide-rich peptides found in the venoms of marine cone snails that can selectively and potently alter the function of ion channels and receptors of the nervous system (5-7). Some have been used as pharmacological probes or developed as drug leads $(8,9)$. One notable example is $\omega$-conotoxin MVIIA (also called ziconotide or Prialt ${ }^{\circledR}$ ), which targets the calcium channel $\mathrm{Ca}_{\mathrm{v}} 2.2$ and is an approved drug to treat neuropathic pain $(10,11)$. Likewise, Vc1.1 reached phase II clinical trials for the treatment of neuropathic pain, and RgIA also entered phase I trials. These latter two peptides have high potency at the $\alpha 9 \alpha 10 \mathrm{nAChR}$, which is considered a pain target, although the full mechanism(s) of analgesia are not understood $(12,13)$, and $G$ protein-coupled receptors such as the GABA $_{B}$ receptor have also been suggested as targets (14-17).

The sequence of conotoxin GeXIVA was identified recently in a transcriptome analysis of the venom duct of Conus generalis (18). This 28-amino acid peptide has four cysteines (Cys I-IV) that can theoretically form three isomers depending on the disulfide connections: globular $\left(\mathrm{Cys}^{\mathrm{I}}-\mathrm{Cys}^{\mathrm{III}}\right.$ and $\mathrm{Cys}^{\mathrm{II}}-$ $\left.\mathrm{Cys}^{\mathrm{IV}}\right)$, ribbon $\left(\mathrm{Cys}^{\mathrm{I}}-\mathrm{Cys}^{\mathrm{IV}}\right.$ and $\left.\mathrm{Cys}{ }^{\mathrm{II}}-\mathrm{Cys}{ }^{\mathrm{III}}\right)$, or bead $\left(\mathrm{Cys}^{\mathrm{I}}-\right.$ $\mathrm{Cys}^{\mathrm{II}}$ and $\mathrm{Cys}^{\mathrm{III}}-\mathrm{Cys}^{\mathrm{IV}}$ ) as shown in Fig. 1. Surprisingly, all three isomers of GeXIVA inhibit the rat $\alpha 9 \alpha 10 \mathrm{nAChR}$ with similar potency, although the bead and ribbon isomers are slightly more potent than the globular $\left(\mathrm{IC}_{50}\right.$ of the bead $=4.6 \mathrm{nM}$; ribbon $=7.0 \mathrm{nM}$; and globular $=22.7 \mathrm{nM})(18)$. NMR structure calculations have shown that ribbon GeXIVA is flexible while still having a more defined structure than the other two isomers (18). These isomers exhibit higher or similar potency at rat $\alpha 9 \alpha 10$ nAChR compared with Vc1.1 (19) or RgIA (20). In addition, the ribbon and bead isomers of GeXIVA showed promise in relieving neuropathic pain in a chronic constriction injury model and also in a tail-flick model of acute pain (21).

Peptides, including conotoxins, typically have low oral bioavailability and are easily degraded by proteases in vivo, thus decreasing their therapeutic potential (22-24). Over the last decade, cyclic peptides have been discovered in animals, plants, fungi, and bacteria and offer clues toward improving the stability of peptides (25-27). Head-to-tail cyclic peptides are typically more resistant to thermal or enzymatic degradation than their linear counterparts $(28,29)$. Improving the stability of conotoxins in biological fluids using backbone cyclization was initially inspired by research into naturally occurring cyclic 


\section{Cyclization improves selective folding of conotoxin GeXIVA}

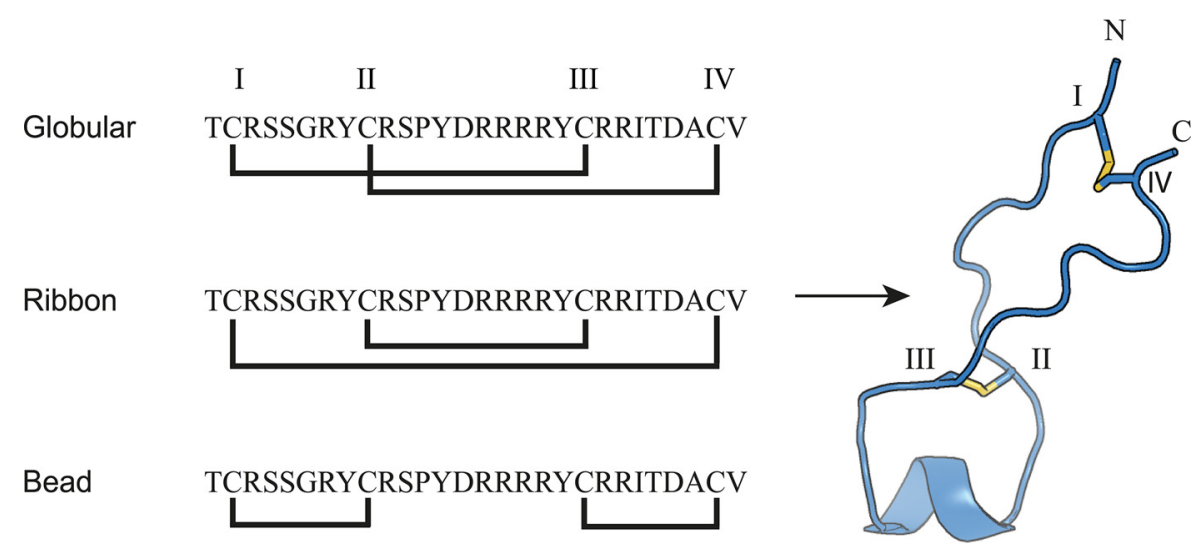

Figure 1. The three isomers of $\alpha \mathrm{O}$-conotoxin GeXIVA and the 3D NMR solution structure of ribbon GeXIVA (18). Cys residues are labeled with Roman numerals $(I-I)$, and the disulfide bonds are shown as yellow sticks. The structure shown for the ribbon GeXIVA is the lowest energy conformer from an ensemble of 10 NMR models.

peptides $(29,30)$ and is a proven strategy to improve the stability of peptides, including conotoxins (31). For example, the stability of $\alpha$-conotoxins MII, ImI, Vc1.1, RgIA, AuIB, and $\chi$-conotoxin MrIA was significantly improved through backbone cyclization, and most of the cyclic peptides had similar or improved activity compared with their parent peptides (32). Most notably, Vc1.1 became orally active in animal models of pain after backbone cyclization (33). The length and amino acid composition of the linker used to join the $\mathrm{N}$ and $\mathrm{C}$ termini of the parent peptide are vital factors for backbone cyclization. For example, the length of the linker has been shown to modulate the yields of the three isomers of framework I conotoxins (corresponding to a $\mathrm{CC}-\mathrm{C}-\mathrm{C}$ pattern) and influence their biological activities (34-38).

Here we investigated whether a similar strategy could be used for $\alpha$-conotoxin GeXIVA. We used backbone cyclization to control the selective formation of the ribbon isomer and investigated the effects of cyclization on structure, activity, and stability. The ribbon isomer is formed by the oxidation of two cysteine residues located near the $\mathrm{N}$ and $\mathrm{C}$ termini of the peptide, suggesting that backbone cyclization could be used to direct the selective formation of the resultant disulfide bond. The three isomers of linear GeXIVA and a suite of cyclic ribbon GeXIVA analogs were synthesized, and their serum stabilities and biological activities at the human $\alpha 9 \alpha 10$ (h $\alpha 9 \alpha 10)$ nAChR were tested.

\section{Results}

\section{Cyclic GeXIVA ribbon isomer retains native structure}

NMR structure calculations for ribbon GeXIVA (18) showed that its $\mathrm{N}$ and $\mathrm{C}$ termini are maintained in close proximity ( $\sim 6.4 \AA$ ) by a disulfide bridge between the first and last Cys residues (Fig. 1). Five linkers were designed using molecular modeling to bridge the termini, and all were geometrically compatible with the linear peptide structure, with the cyclic backbones maintained within 1 A root-mean-square deviation (RMSD) of the linear peptide. The data suggested that even a one-residue linker is sufficient to cyclize the backbone of ribbon GeXIVA without perturbing structure. Models of cyclic GeXIVA with minimum perturbation of the parent peptide backbone are shown in Fig. 2. For experimental validation, we focused on three short linkers (G, GG, and GAG) and the three corresponding cyclic variants: ribbon cGeXIVA_G, ribbon cGeXIVA_GG, and ribbon cGeXIVA_GAG. The three isomers of linear GeXIVA and the three cyclic ribbon analogs were synthesized using orthogonal protection of the cysteine side chains to orient the folding toward a unique disulfide isomer. The yields of three isomers of linear GeXIVA and cyclic ribbon GeXIVA were low $(<1 \%)$ using a two-step oxidation method. Although we optimized the purification procedure, globular GeXIVA could not be completely purified. We therefore explored an alternative one-pot synthetic approach.

\section{One-pot oxidative folding}

Non-directed oxidative folding of GeXIVA and cGeXIVA GG was carried out in $\mathrm{NH}_{4} \mathrm{HCO}_{3}(\mathrm{pH}$ 8.3) at room temperature (Fig. 3A). For GeXIVA, three major products were formed within $20 \mathrm{~h}$. The three major peaks were observed in the ultraperformance liquid chromatography trace, accounting for $\sim 25$, 45 , and $30 \%$ of the total peptide, respectively. Analysis of each peak using a TripleTOF 5600 mass spectrometer (AB SCIEX, Concord, Canada) with a nanoelectrospray ionization source revealed masses of 3450.62 , 3450.62, and $3450.63 \mathrm{Da}$, respectively, each corresponding to fully oxidized GeXIVA. The three peaks were unambiguously identified by co-elution with the globular GeXIVA, bead GeXIVA, and ribbon GeXIVA isomers. The HPLC peaks of ribbon and bead GeXIVA partly overlapped and were difficult to separate (Fig. $3 A, 24 h$ ). Interestingly, a single peak representing the majority of the oxidized forms transiently appeared from 1 to $4 \mathrm{~h}$ and then disappeared from 4 to $8 \mathrm{~h}$ (Fig. $3 A$, black asterisk). This transient peak partly overlaps with the major final product (Fig. 3A, 24h), which was identified as globular GeXIVA. We hypothesized that the globular isomer might form within $4 \mathrm{~h}$ and then gradually convert into other isomers. We incubated globular GeXIVA in $\mathrm{NH}_{4} \mathrm{HCO}_{3}(\mathrm{pH}$ 8.3) at room temperature at a final concentration of $20 \mu \mathrm{m}$ and the globular GeXIVA was found to be very stable in the folding buffer for $24 \mathrm{~h}$ (data not shown), suggesting that the first major peak at $4 \mathrm{~h}$ mainly comprises intermediate forms with similar retention time to the globular isomer.

The one-step oxidation of reduced cGeXIVA_GG was complete at $16 \mathrm{~h}$, whereas some intermediates could still be seen at 


\section{Cyclization improves selective folding of conotoxin GeXIVA}

A

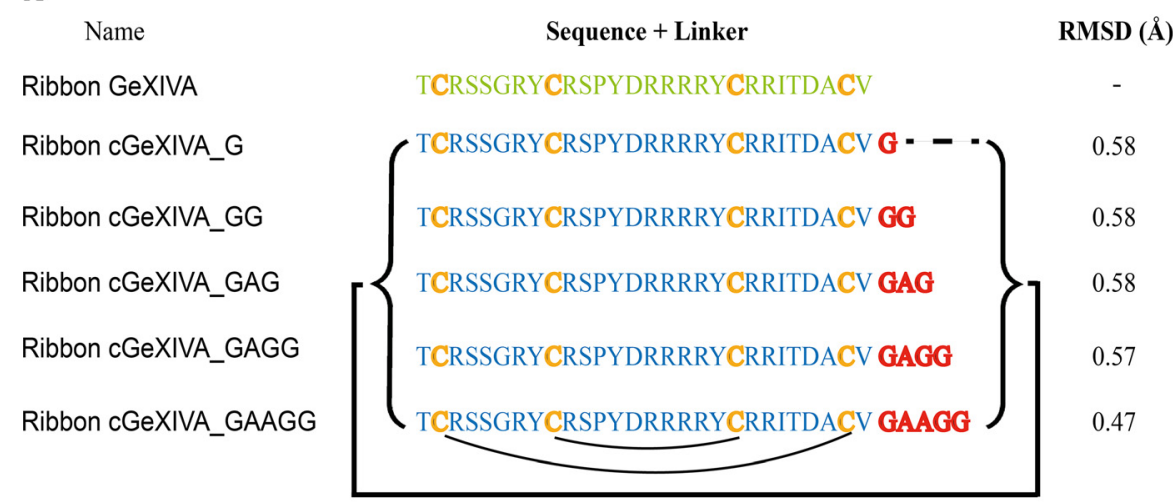

B

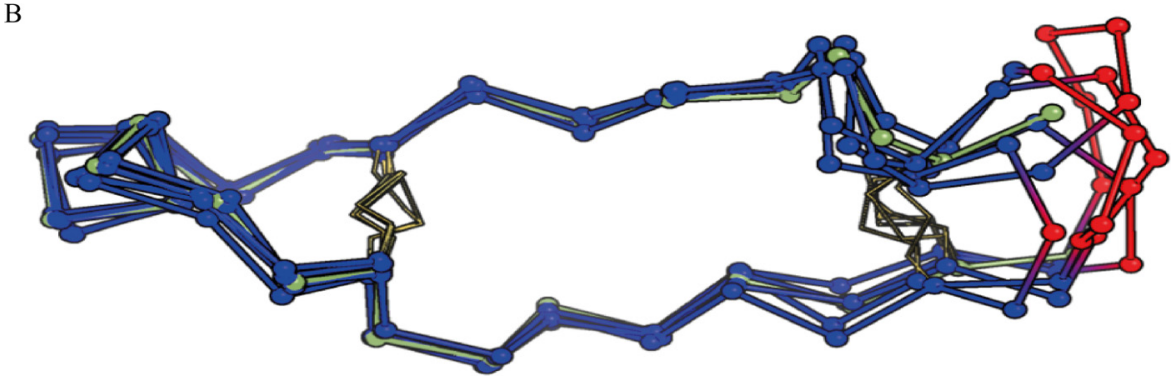

Figure 2. Amino acid sequences and NMR structure of ribbon GeXIVA and cyclic ribbon isomers of GeXIVA. $A$, amino acid sequences of ribbon GeXIVA and cyclic analogs. The backbone cyclization of ribbon GeXIVA was carried out using different sized linkers (highlighted in red) spanning its $\mathrm{N}$ and $\mathrm{C}$ termini (indicated by the black bracket and line). The black curved lines below the sequence show the ribbon disulfide connectivity. The $\alpha$-carbon (C $\alpha$ ) RMSD of the backbone for the parent peptide and molecular models of the cyclic peptides are shown in the last column. $B$, NMR solution structure of ribbon GeXIVA (green) and models of cyclic variants (backbones in blue and linkers in red). The disulfide bonds are represented by yellow sticks, and the C $\alpha$ are shown as balls.

that time for the linear GeXIVA. Only three products were formed, all of mass $3546.66 \mathrm{Da}$, corresponding to that of the fully oxidized cGeXIVA_GG. The third major peak accounted for $86 \%$ of the total peptide content and was confirmed as being the ribbon isomer by co-elution. The two other peaks are presumably the globular and bead isomers. In contrast to linear GeXIVA, the retention time of globular, bead, and ribbon isomers of cGeXIVA_GG separate well (Fig. 3A) as the linker engenders ribbon cGeXIVA_GG with a larger hydrophobic patch than ribbon GeXIVA (Fig. 3B, green), which could explain its later retention time. Four intermediate forms were identified over the time course. The major intermediate (Fig. 3A, blue asterisk and labeled $I_{1}$ ) was the most abundant of the oxidized forms from 1 to $4 \mathrm{~h}$. The major intermediate $\mathrm{I}_{1}$ of cGeXIVA_GG was isolated, and its mass was $3548.66 \mathrm{Da}$, indicating that it has only one disulfide bond. The masses of the three minor intermediates were each $3546.65 \mathrm{Da}$, suggesting that they have two disulfide bonds (all labeled $I_{2}$ in Fig. $3 A$ ).

\section{NMR analyses of ribbon GeXIVA and ribbon cGeXIVA_GG}

A comparison of the secondary $\alpha \mathrm{H}$ chemical shifts of ribbon GeXIVA with those of ribbon cGeXIVA_GG suggested very little difference in structure between the linear and cyclic analogs (Fig. 4A). The different chemical environment created by the presence of the cyclizing linker can easily explain the minimal shift differences near the termini. Overlapping peaks in the 2D NMR spectra prevented the unambiguous assignment of the cGeXIVA_G and cGeXIVA_GAG spin systems.

The 3D structure of cGeXIVA_GG was calculated with a total of 171 distance restraints and found to contain a short $3_{10}$-helix (from Pro ${ }^{12}$ to $\mathrm{Arg}^{16}$; Fig. $4 B$ ). The Ser $^{11}-$ Pro $^{12}$ peptide bond was determined to adopt a trans configuration, similar to the configuration of this bond in the ribbon and bead isomers of linear GeXIVA (18). As shown for ribbon GeXIVA (18), the loop formed between $\mathrm{Cys}^{9}$ and $\mathrm{Cys}^{20}$ overlays reasonably well between NMR models (RMSD of $1.38 \pm 0.56 \AA$ across backbone atoms of residues 9-20; Table 1), although the remainder of the peptide is somewhat disordered, suggesting a degree of flexibility. We thus used NMR spin relaxation measurements to characterize the backbone dynamics of cGeXIVA_GG (Fig. 5 and Table 2). Heteronuclear $\mathrm{T}_{1}$ and NOEs were measured and used to derive order parameters reflective of motion of the $\mathrm{C} \alpha-\mathrm{H} \alpha$ bonds. Because of spectral overlap, only 18 of the 30 residues could be analyzed. Nevertheless, the order parameters $(0.53-0.81$; mean of 0.63$)$ suggest that cGeXIVA_GG is moderately flexible, which agrees with the geometric analysis of the lowest energy structures. The least flexible region is at the $\mathrm{C}$-terminal end of the $\mathrm{Cys}^{9}$ to $\mathrm{Cys}^{20}$ loop.

\section{Ribbon cGeXIVA_GG and ribbon GeXIVA are equipotent inhibitors of the human $\alpha 9 \alpha 10$ nAChR subtype}

Linear GeXIVA isomers have been shown to selectively and potently inhibit the rat $\alpha 9 \alpha 10 \mathrm{nAChR}$ subtype (18). Here, globular, bead, and ribbon isomers of linear GeXIVA, and cyclic constructs of ribbon GeXIVA (cGeXIVA_G, cGeXIVA_GG, and ribbon cGeXIVA_GAG) were tested for their functional activity at the h $\alpha 9 \alpha 10$ nAChR subtype heterologously expressed in Xenopus laevis oocytes. All three cyclic ribbon constructs tested at $100 \mathrm{~nm}$ inhibited ACh-evoked currents mediated by h $\alpha 9 \alpha 10 \mathrm{nAChRs}$ by $\sim 60-70 \%(n=4-6)$. Similarly, 
A

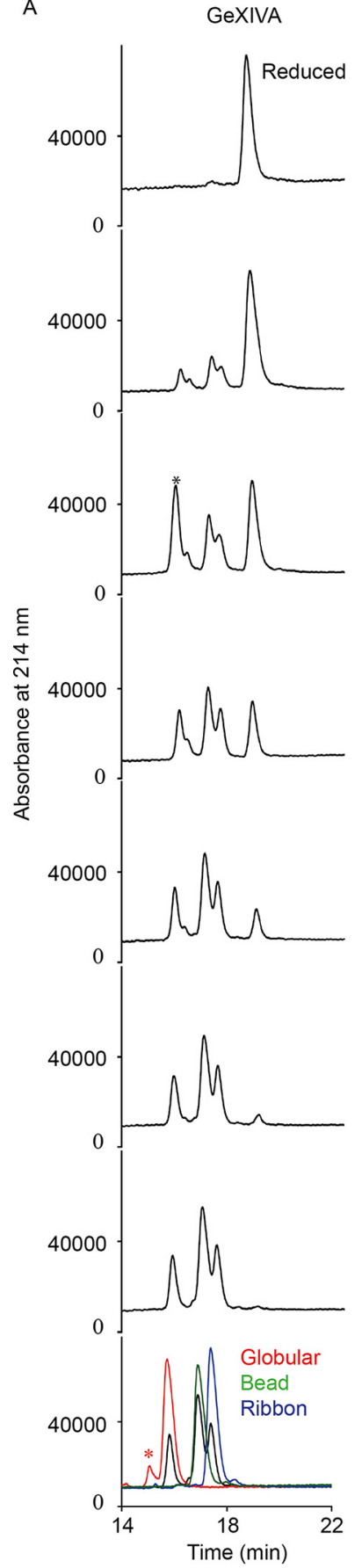

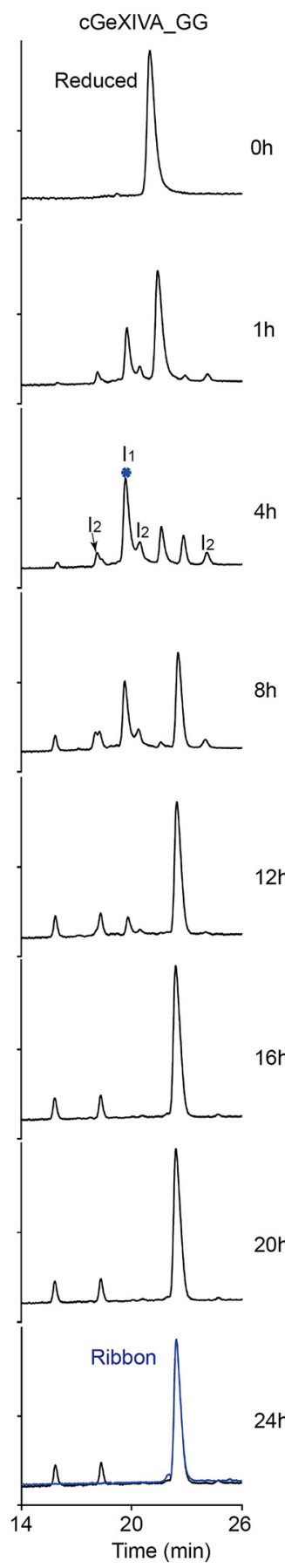

h

$2 \mathrm{~h}$
B

Ribbon GeXIVA
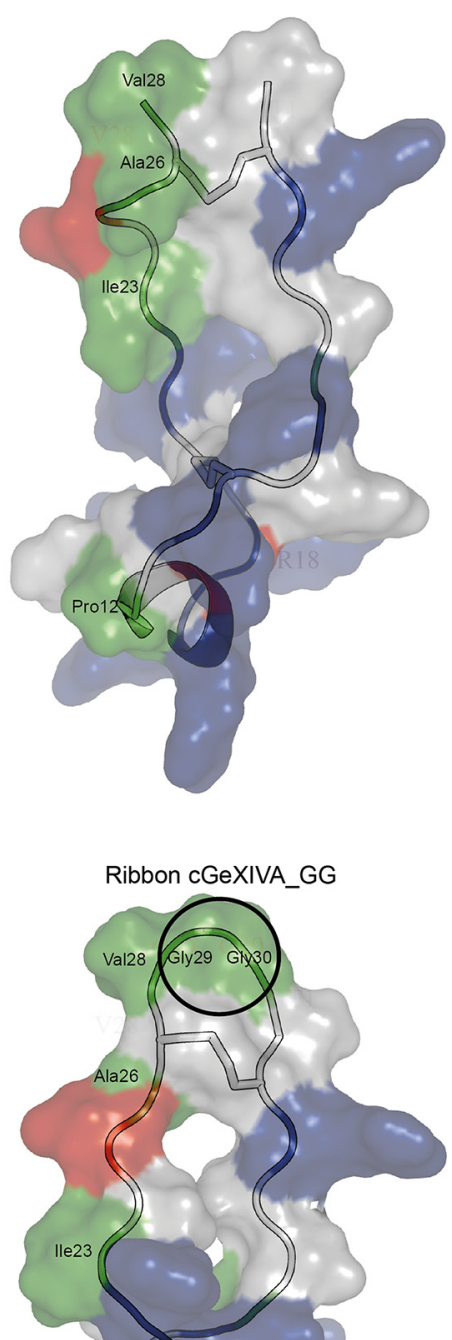

Figure 3. Time course of the oxidative folding of GeXIVA and cGeXIVA_GG. A, HPLC traces of samples taken at various times during the random folding process. For GeXIVA, the black asterisk indicates that the peak occurring in the folding process of GeXIVA comprises intermediate forms with similar retention time to the globular isomer, and the red asterisk indicates an impurity. The globular, bead, and ribbon GeXIVA from two-step oxidations are shown as red, green, and blue traces, respectively. For CGeXIVA_GG, the blue asterisk indicates the major intermediate occurring in the folding process of cGeXIVA_GG. The ribbon cGeXIVA GG from two-step oxidation is shown as a blue trace. $I_{1}$ represents the intermediate with one disulfide bond, and $I_{2}$ represents the intermediates with two disulfide bonds. B, surface representations of ribbon GeXIVA and ribbon CGeXIVA_GG. Positively charged residues are shown in blue, negative residues are red, polar residues are white, and hydrophobic residues are green. Surface representations were created using the program PyMOL. Cyclization of ribbon GeXIVA resulted in an additional hydrophobic patch (circle) in cGeXIVA_GG.

the bead $(n=5)$ and ribbon isomers $(n=8)$ of GeXIVA inhibited the h $\alpha 9 \alpha 10$ ACh-evoked current amplitude by $\sim 60-70 \%$. In contrast, the globular GeXIVA was less potent, inhibiting h $\alpha 9 \alpha 10$ ACh-evoked currents by $\sim 40 \%(n=12)$ (Fig. 6A).

The concentration-dependent activity of globular and ribbon GeXIVA, and ribbon cGeXIVA_GG at h $\alpha 9 \alpha 10$ nAChRs were determined (Fig. 6B). All peptides reversibly inhibited ACh-evoked currents in a concentration-dependent manner, giving $\mathrm{IC}_{50}$ values of $198.6 \pm 18.9 \mathrm{~nm}(n=4-12)$ for globular GeXIVA, $35.1 \pm 2.7 \mathrm{~nm}(n=4-8)$ for ribbon GeXIVA and $37.6 \pm 4.9 \mathrm{~nm}(n=4-11)$ for ribbon cGeXIVA_GG. Consistent with the previously reported potency of globular and ribbon GeXIVA at rat $\alpha 9 \alpha 10 \mathrm{nAChRs}$, the globular isomer of GeXIVA 


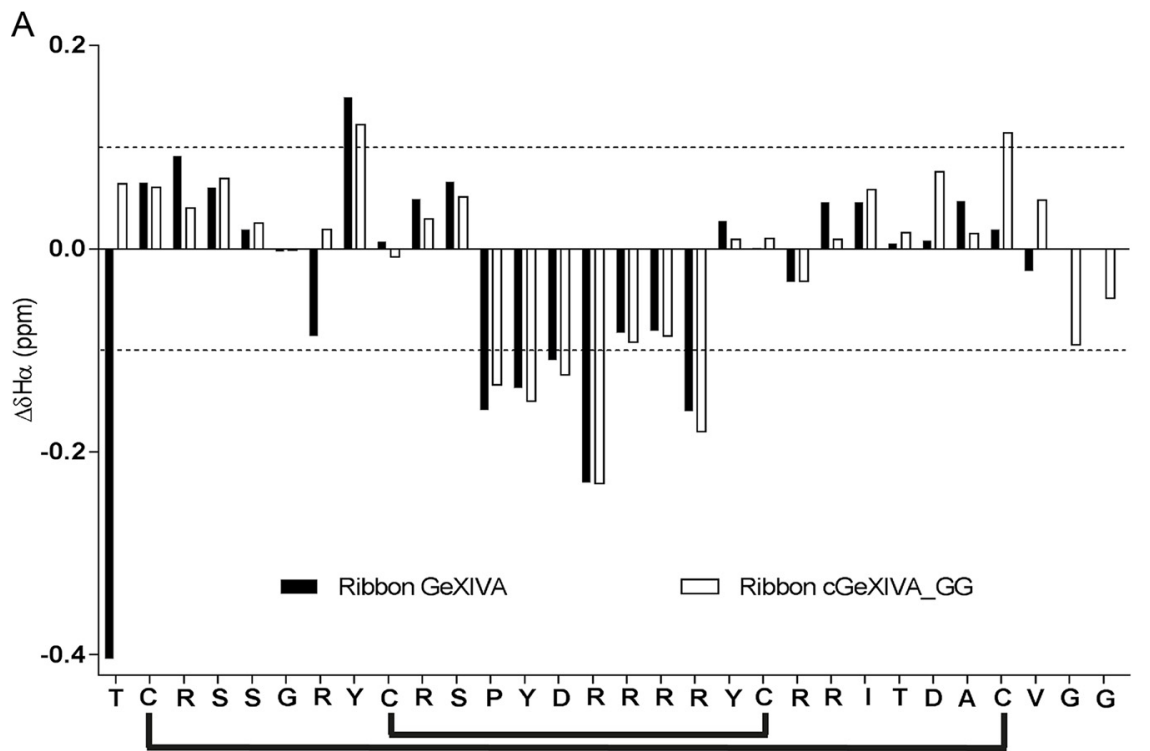

B

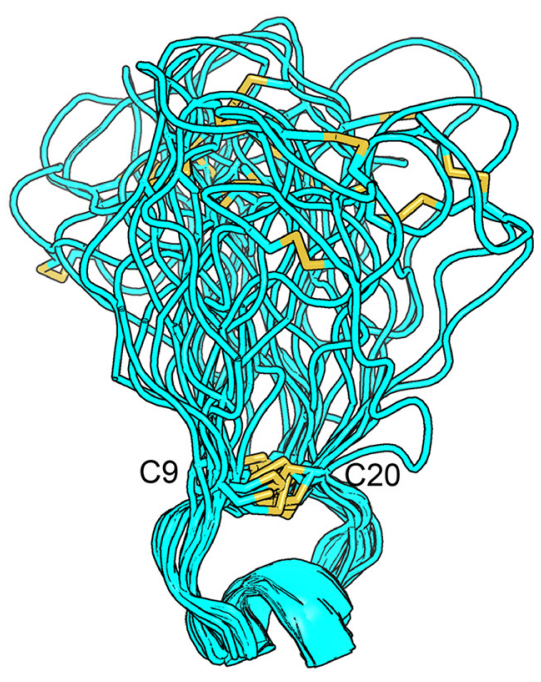

Figure 4. Structural characterization of cGeXIVA_GG. $A$, secondary $\alpha \mathrm{H}$ chemical shifts of ribbon GeXIVA and ribbon $c G e X I V A \_G G(\Delta \delta H \alpha)$. The overall secondary structures of ribbon GeXIVA and ribbon cGeXIVA_GG are similar, and both peptides display a $3{ }_{10}$-helix from Pro ${ }^{12}$ to Arg ${ }^{16}$. The black lines below the sequence show the ribbon disulfide connectivity. B, ribbon diagram of the NMR solution structure of cGeXIVA_GG. Models were overlaid over the Cys ${ }^{9}-C y s^{20}$ segment. Disulfide bonds are shown in yellow.

\section{Table 1}

Statistical analysis of cGeXIVA_GG structures

All statistics are given as means \pm S.D.

\begin{tabular}{|c|c|}
\hline \multicolumn{2}{|l|}{ Experimental restraints } \\
\hline Total no. distance restraints & 171 \\
\hline Intraresidue & 90 \\
\hline Sequential & 73 \\
\hline Medium range, $i-j<5$ & 8 \\
\hline Long range, $i-j \geq 5$ & 0 \\
\hline Hydrogen bond restraints & 2 \\
\hline Dihedral angle restraints & 32 \\
\hline NOE violations exceeding $0.3 \AA$ & 0 \\
\hline Dihedral violations exceeding $2.0 \AA$ & 0 \\
\hline \multicolumn{2}{|l|}{ RMSD from mean structure, $\AA$} \\
\hline Backbone atoms (residues 9-20) & $1.38 \pm 0.56$ \\
\hline All heavy atoms (residues 9-20) & $3.33 \pm 0.98$ \\
\hline \multicolumn{2}{|l|}{ Stereochemical quality ${ }^{a}$} \\
\hline Residues in most favored Ramachandran region, \% & $77.9 \pm 8.9$ \\
\hline Ramachandran outliers, $\%$ & $1.4 \pm 1.8$ \\
\hline Unfavorable side-chain rotamers, $\%$ & $3.7 \pm 2.6$ \\
\hline Clashscore, all atoms & $0.1 \pm 0.4$ \\
\hline Overall MolProbity score & $1.6 \pm 0.3$ \\
\hline
\end{tabular}

${ }^{a}$ According to MolProbity (76).

had lower potency at h $\alpha 9 \alpha 10 \mathrm{nAChRs}$ than the ribbon analog. Ribbon GeXIVA and ribbon cGeXIVA_GG had similar IC $_{50}$ values, suggesting that backbone cyclization had no impact on the potency of inhibition at h $\alpha 9 \alpha 10 \mathrm{nAChRs}$.

\section{Serum stability of linear GeXIVA and ribbon CGeXIVA isomers}

Stability assays for the ribbon isomer of GeXIVA and its three cyclic analogs were carried out in human serum. All four peptides degraded within $2 \mathrm{~h}$, but the ribbon cGeXIVA_GG was slightly more stable than the other peptides (data for cGeXIVA_G and GeXIVA_GAG not shown). Subsequently, the stability of the three isomers of linear GeXIVA and of ribbon cGeXIVA_GG was compared with that of $\alpha$-conotoxin cVc1.1 (33) in 25\% human serum. The positive control, cVc1.1, was highly stable, whereas only $\sim 20 \%$ of the three isomers of GeXIVA remained after $4 \mathrm{~h}$ of incubation. Ribbon cGeXIVA_ GG was more stable than the three linear isomers of GeXIVA $(p<0.001)$ at the 4 -h time point, with 38\% of cGeXIVA_GG remaining (Fig. 7).

\section{Discussion}

The $\alpha 9 \alpha 10$ nAChR mediates efferent olivocochlear innervations in outer hair cells and modulates immune responses in lymphocytes $(39-41)$. It is also reported to be implicated in pain and cancer $(42,43)$. Only a handful of $\alpha$-conotoxins is currently known to selectively inhibit the $\alpha 9 \alpha 10 \mathrm{nAChR}(18$, 44-46), so studies of new examples such as GeXIVA are important for defining receptor specificity. Furthermore, previous studies have highlighted the value of backbone cyclization to enhance the biopharmaceutical properties of $\alpha$-conotoxins $(33,47)$, and so here we attempted to apply this approach to GeXIVA.

Molecular modeling was used to design linkers comprising only a small number of amino acids that would introduce minimal constraints into the peptide fold. A recent study highlighted the importance of the distance between the $\mathrm{N}$ and $\mathrm{C}$ termini in designing cyclizing linkers (48), but considering distances alone will not address limitations caused by accessible conformations of backbones nor the orientation of the termini. Structural perturbations may be introduced unintentionally into a cyclic peptide when a linker is designed on the basis of distance only, ultimately decreasing biological activity $(47,49)$. In the case of ribbon GeXIVA, modeling showed that the proximity of the termini would allow cyclization with a single residue linker without affecting the structure. Because non-neutral amino acids in the cyclizing linker sequence can have a negative effect on biological activity (50), only Gly and Ala amino acids were used in the linkers in the current study. These residues are small, flexible, non-charged, and likely to have minimal interference with biological activity. No more than two sequential Gly or Ala were used in any individual linker to avoid overlapping peaks in NMR spectra and thus avoid spectral assignment 

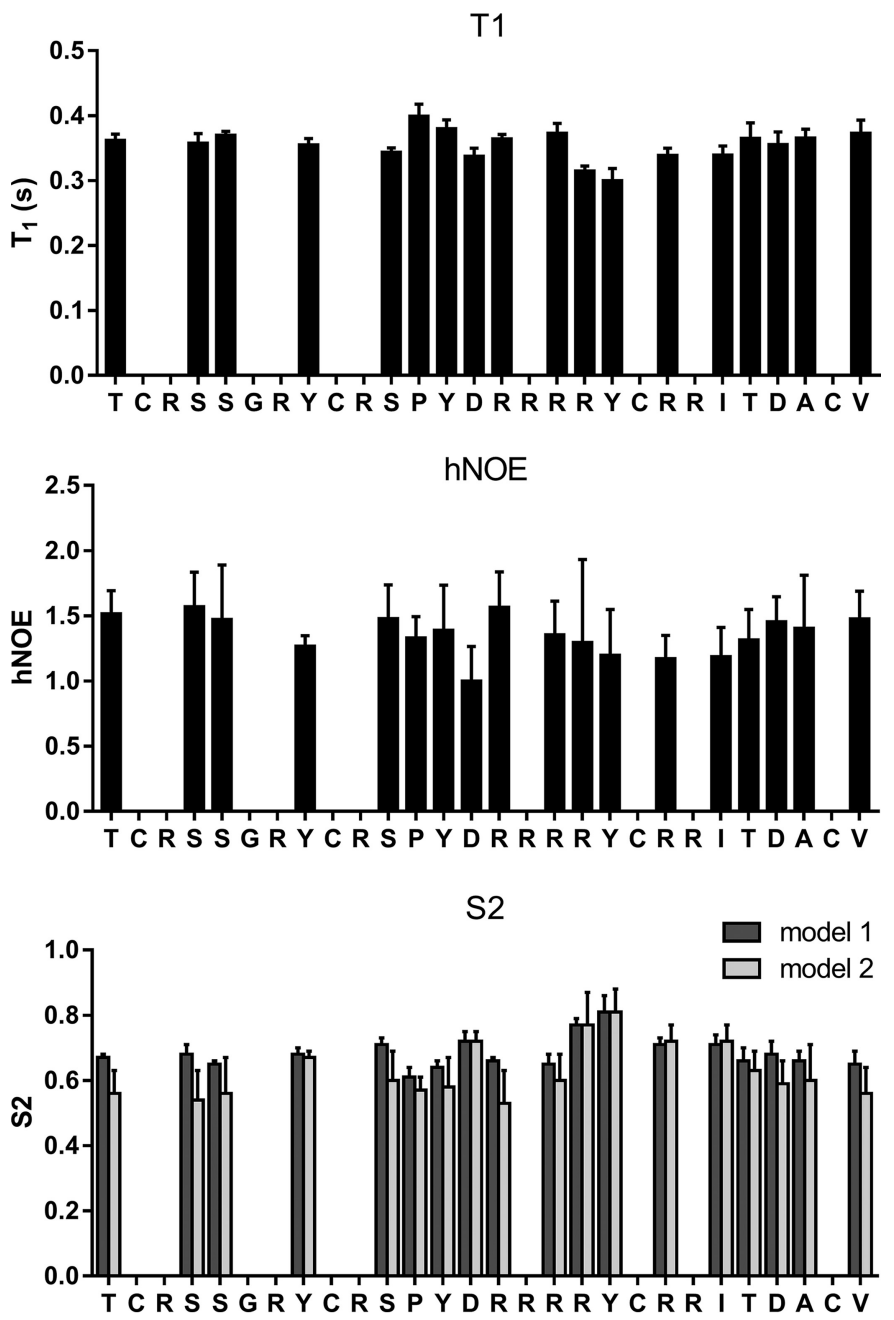

Figure 5. Experimental relaxation data and derived order parameters for cGeXIVA_GG. $T_{1}$ (top panel) and heteronuclear NOE (middle panel) values for the $\mathrm{C} \alpha$ nuclei were measured at $600 \mathrm{MHz}$. Errors are shown as standard deviations of triplicate measurements. Only 18 of the residues could be analyzed. A model-free analysis was used to derive order parameters (bottom panel). Models 1 and 2 of model-free were used in the analysis. Errors, shown as standard deviation, were estimated using a Monte Carlo algorithm.

difficulties. Linkers composed of Gly and Ala residues have been successfully used to cyclize the $\alpha$-conotoxins MII, RgIA, and Vc1.1, without adversely affecting biological activity or structure $(33,47,49)$.

The linkers used in this study did not affect the activity and structure of ribbon GeXIVA. Indeed, all cyclic ribbon variants, i.e. cGeXIVA_G, cGeXIVA_GG, and cGeXIVA_GAG, had similar activity to the linear ribbon form at the $h \alpha 9 \alpha 10 \mathrm{nAChR}$. Although no structural data from peptides cyclized with a G or GAG linker were obtained because of NMR spectral overlap, the GG linker did yield a cyclized peptide with a very similar conformation to the linear ribbon GeXIVA. Alignment of the lowest energy model generated from NMR data and an analysis of the backbone relaxation measurements suggests that the cyclic variant is most rigid in the $\mathrm{Cys}^{9}-\mathrm{Cys}^{20}$ loop region but slightly more flexible in the remainder of the molecule. It has recently been shown that backbone cyclization can enhance or retain backbone rigidity for three different classes of peptides, including for the conotoxin Vc1.1 (51). Cyclization appears to have less of a rigidifying effect in GeXIVA.
Table 2

Relaxation data, fitted parameters, and error estimates for cGeXIVA_ GG

\begin{tabular}{|c|c|c|c|c|c|c|c|c|c|c|}
\hline $\operatorname{Res}^{a}$ & Data $^{\mathrm{b}}$ & $\mathbf{T}_{1}(\mathbf{s})^{\mathbf{c}}$ & $\mathrm{NOE}^{\mathrm{c}}$ & $\tau_{0}$ & $e^{2} r^{d}$ & $\tau_{\mathbf{i}}$ & $e^{2} r^{d}$ & $\mathrm{~S}^{2}$ & $e^{2} r^{d}$ & RMSD $^{\mathbf{e}}$ \\
\hline \multirow[t]{3}{*}{ T1 } & $\operatorname{Exp}^{\mathrm{f}}$ & 0.36 & 1.51 & & & & & & & \\
\hline & $\mathrm{ml}$ & 0.36 & 1.23 & 1.38 & 0.08 & & & 0.67 & 0.01 & \\
\hline & $\mathrm{m} 2$ & 1.51 & 1.39 & 1.39 & 0.02 & 49.17 & 27.53 & 0.56 & 0.07 & \\
\hline $\mathrm{C} 2$ & $\operatorname{Exp}$ & $N A^{\mathrm{g}}$ & $N A$ & & & & & & & \\
\hline R3 & Exp & $N A$ & $N A$ & & & & & & & \\
\hline \multirow[t]{3}{*}{54} & $\operatorname{Exp}$ & 0.36 & 1.57 & & & & & & & \\
\hline & $\mathrm{m} 1$ & 0.36 & 1.23 & 1.38 & 0.08 & & & 0.68 & 0.03 & 0.64 \\
\hline & $\mathrm{m} 2$ & 0.36 & 1.57 & 1.39 & 0.02 & 58.79 & 31.61 & 0.54 & 0.09 & 0.00 \\
\hline \multirow[t]{3}{*}{ S5 } & $\operatorname{Exp}$ & 0.37 & 1.47 & & & & & & & \\
\hline & $\mathrm{m} 1$ & 0.37 & 1.23 & 1.38 & 0.08 & & & 0.65 & 0.01 & 0.29 \\
\hline & $\mathrm{m} 2$ & 0.37 & 1.47 & 1.39 & 0.02 & 40.48 & 41.41 & 0.56 & 0.11 & 0.00 \\
\hline G6 & $\operatorname{Exp}$ & $N A$ & $N A$ & & & & & & & \\
\hline R7 & $\operatorname{Exp}$ & $N A$ & $N A$ & & & & & & & \\
\hline \multirow[t]{3}{*}{ Y8 } & $\operatorname{Exp}$ & 0.35 & 1.27 & & & & & & & \\
\hline & $\mathrm{ml}$ & 0.35 & 1.23 & 1.38 & 0.08 & & & 0.68 & 0.02 & 0.24 \\
\hline & $\mathrm{m} 2$ & 0.35 & 1.27 & 1.39 & 0.02 & 8.30 & 12.68 & 0.67 & 0.02 & 0.00 \\
\hline C9 & $\operatorname{Exp}$ & $N A$ & $N A$ & & & & & & & \\
\hline R10 & Exp & $N A$ & $N A$ & & & & & & & \\
\hline \multirow[t]{3}{*}{ S11 } & Exp & 0.34 & 1.48 & & & & & & & \\
\hline & $\mathrm{m} 1$ & 0.34 & 1.23 & 1.38 & 0.08 & & & 0.71 & 0.02 & 0.48 \\
\hline & $\mathrm{m} 2$ & 0.34 & 1.48 & 1.39 & 0.02 & 50.50 & 36.54 & 0.60 & 0.09 & 0.00 \\
\hline \multirow[t]{3}{*}{ P12 } & $\operatorname{Exp}$ & 0.40 & 1.33 & & & & & & & \\
\hline & $\mathrm{m} 1$ & 0.40 & 1.23 & 1.38 & 0.08 & & & 0.61 & 0.03 & 0.30 \\
\hline & $\mathrm{m} 2$ & 0.40 & 1.33 & 1.39 & 0.02 & 15.00 & 16.53 & 0.57 & 0.04 & 0.00 \\
\hline \multirow[t]{3}{*}{ Y13 } & $\operatorname{Exp}$ & 0.38 & 1.39 & & & & & & & \\
\hline & $\mathrm{m} 1$ & 0.38 & 1.23 & 1.38 & 0.08 & & & 0.64 & 0.02 & 0.23 \\
\hline & $\mathrm{m} 2$ & 0.38 & 1.39 & 1.39 & 0.02 & 26.05 & 32.83 & 0.58 & 0.09 & 0.00 \\
\hline \multirow[t]{3}{*}{ D14 } & $\operatorname{Exp}$ & 0.34 & 1.00 & & & & & & & \\
\hline & $\mathrm{m} 1$ & 0.34 & 1.23 & 1.38 & 0.08 & & & 0.72 & 0.03 & 0.43 \\
\hline & $\mathrm{m} 2$ & 0.34 & 1.23 & 1.39 & 0.02 & 0.00 & 7.88 & 0.72 & 0.03 & 0.43 \\
\hline \multirow[t]{3}{*}{ R15 } & $\operatorname{Exp}$ & 0.36 & 1.57 & & & & & & & \\
\hline & $\mathrm{m} 1$ & 0.36 & 1.23 & 1.38 & 0.08 & & & 0.66 & 0.01 & 0.62 \\
\hline & $\mathrm{m} 2$ & 0.36 & 1.57 & 1.39 & 0.02 & 55.40 & 34.31 & 0.53 & 0.10 & 0.00 \\
\hline R16 & $\operatorname{Exp}$ & $N A$ & $N A$ & & & & & & & \\
\hline \multirow[t]{3}{*}{ R17 } & $\operatorname{Exp}$ & 0.37 & 1.35 & & & & & & & \\
\hline & $\mathrm{ml}$ & 0.37 & 1.23 & 1.38 & 0.08 & & & 0.65 & 0.03 & 0.24 \\
\hline & $\mathrm{m} 2$ & 0.37 & 1.35 & 1.39 & 0.02 & 21.78 & 32.78 & 0.60 & 0.08 & 0.00 \\
\hline R18 & $\operatorname{Exp}$ & 0.31 & 1.29 & & & & & & & \\
\hline & $\mathrm{m} 1$ & 0.31 & 1.23 & 1.38 & 0.08 & & & 0.77 & 0.02 & 0.06 \\
\hline & $\mathrm{m} 2$ & 0.31 & 1.23 & 1.39 & 0.02 & 0.00 & 51.04 & 0.77 & 0.10 & 0.05 \\
\hline Y19 & $\operatorname{Exp}$ & 0.30 & 1.20 & & & & & & & \\
\hline & $\mathrm{m} 1$ & 0.30 & 1.23 & 1.38 & 0.08 & & & 0.81 & 0.05 & 0.05 \\
\hline & $\mathrm{m} 2$ & 0.30 & 1.23 & 1.39 & 0.02 & 0.00 & 44.45 & 0.81 & 0.07 & 0.05 \\
\hline C20 & $\operatorname{Exp}$ & $N A$ & $N A$ & & & & & & & \\
\hline R21 & $\operatorname{Exp}$ & 0.34 & 1.17 & & & & & & & \\
\hline & $\mathrm{m} 1$ & 0.34 & 1.23 & 1.38 & 0.08 & & & 0.71 & 0.02 & 0.17 \\
\hline & $\mathrm{m} 2$ & 0.34 & 1.23 & 1.39 & 0.02 & 0.00 & 21.77 & 0.72 & 0.05 & 0.16 \\
\hline R22 & Exp & $N A$ & $N A$ & & & & & & & \\
\hline I23 & Exp & 0.34 & 1.19 & & & & & & & \\
\hline & $\mathrm{m} 1$ & 0.34 & 1.23 & 1.38 & 0.08 & & & 0.71 & 0.03 & 0.10 \\
\hline & $\mathrm{m} 2$ & 0.34 & 1.23 & 1.39 & 0.02 & 0.00 & 25.60 & 0.72 & 0.05 & 0.10 \\
\hline T24 & $\operatorname{Exp}$ & 0.37 & 1.31 & & & & & & & \\
\hline & $\mathrm{m} 1$ & 0.36 & 1.23 & 1.38 & 0.08 & & & 0.66 & 0.04 & 0.18 \\
\hline & $\mathrm{m} 2$ & 0.37 & 1.31 & 1.39 & 0.02 & 16.23 & 28.58 & 0.63 & 0.06 & 0.00 \\
\hline D25 & $\operatorname{Exp}$ & 0.36 & 1.45 & & & & & & & \\
\hline & $\mathrm{m} 1$ & 0.36 & 1.23 & 1.38 & 0.08 & & & 0.68 & 0.04 & 0.58 \\
\hline & $\mathrm{m} 2$ & 0.36 & 1.45 & 1.39 & 0.02 & 41.87 & 27.89 & 0.59 & 0.07 & 0.00 \\
\hline A26 & $\operatorname{Exp}$ & 0.37 & 1.40 & & & & & & & \\
\hline & $\mathrm{m} 1$ & 0.37 & 1.23 & 1.38 & 0.08 & & & 0.66 & 0.03 & 0.21 \\
\hline & $\mathrm{m} 2$ & 0.37 & 1.40 & 1.39 & 0.02 & 31.06 & 39.01 & 0.60 & 0.11 & 0.00 \\
\hline C27 & $\operatorname{Exp}$ & $N A$ & $N A$ & & & & & & & \\
\hline & $\mathrm{m} 1$ & 0.37 & 1.23 & 1.38 & 0.08 & & & 0.65 & 0.04 & 0.58 \\
\hline & $\mathrm{m} 2$ & 0.37 & 1.48 & 1.39 & 0.02 & 40.22 & 23.05 & 0.56 & 0.08 & 0.00 \\
\hline G29 & $\operatorname{Exp}$ & $N A$ & $N A$ & & & & & & & \\
\hline G30 & $\operatorname{Exp}$ & $N A$ & $N A$ & & & & & & & \\
\hline 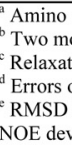 & $\begin{array}{l}\text { on data } ~ \\
\text { btained } \mathrm{f}\end{array}$ & $\begin{array}{l}\text { rom } 20 \mathrm{~N} \\
\text { t-mean-s } \\
\text { ere down }\end{array}$ & $\begin{array}{l}\text { re analy } \\
\text { tt } 600.13 \\
\text { onte Car } \\
\text { uared de } \\
\text { weighte }\end{array}$ & $\begin{array}{l}\mathrm{l}-\mathrm{m} 1 \\
\mathrm{~Hz} \\
\text { simulat } \\
\text { tion be } \\
\text { accou }\end{array}$ & $\begin{array}{l}\text { een ex } \\
\text { for the }\end{array}$ & $\begin{array}{l}\text { erimenta } \\
r \text { intrinsi }\end{array}$ & $\begin{array}{l}\text { nd fitte } \\
\text { ly high }\end{array}$ & $\begin{array}{l}T_{1} \text { and } \\
\text { errors }\end{array}$ & $F_{1}$ & The \\
\hline$R M S D=$ & $\sum 1$ & $\frac{\frac{1}{e x p}-T_{1}^{c}}{\sigma_{T_{1}}{ }^{2}}$ & $\left.{ }^{a l c}\right)^{2}+$ & $\sum \frac{(1}{1}$ & $E^{\exp }-$ & $\frac{V O E^{c a l c}}{2}$ & & & & \\
\hline
\end{tabular}

${ }^{\mathrm{f}}$ Exp refers to the experimentally determined $\mathrm{T} 1$ and NOE values; theoretical values for models $\mathrm{ml}$ and $\mathrm{m} 2$ are also shown

${ }^{\mathrm{g}} \mathrm{NA}$, not assigned due to spectral overlap

The non-directed oxidation of GeXIVA resulted in the preferential formation of the bead isomer, followed by the ribbon and globular forms, which interestingly parallels their biological activity (18). By contrast, two previous studies employing the one-step oxidation of $\alpha$-conotoxins showed preferential 


\section{Cyclization improves selective folding of conotoxin GeXIVA}
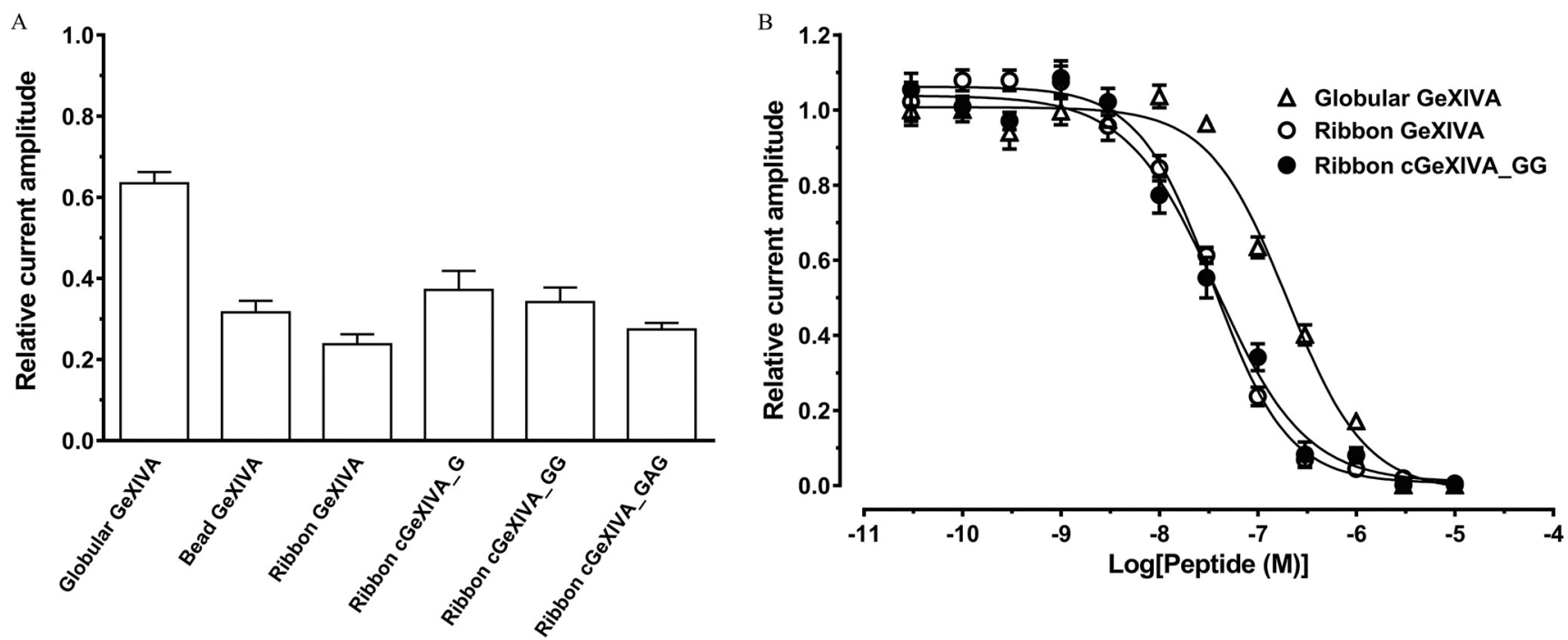

Figure 6. Inhibition of human $\alpha 9 \alpha 10$ nAChR by linear GeXIVA and ribbon cGeXIVA isomers. $A$, bar graph of globular GeXIVA, bead GeXIVA, ribbon GeXIVA, ribbon cGeXIVA_G, ribbon cGeXIVA_GG, and ribbon cGeXIVA_GAG (100 nM) inhibition of ACh-evoked peak current amplitude mediated by h $\alpha 9 \alpha 10$ nAChRs. Whole-cell h $\alpha 9 \alpha 10 \mathrm{nAChR-mediated} \mathrm{currents} \mathrm{were} \mathrm{activated} \mathrm{by} 6 \mu \mathrm{m}$ ACh. B, concentration-response curves of globular and ribbon GeXIVA and ribbon cGeXIVA_GG inhibition of ACh-evoked currents mediated by h $\alpha 9 \alpha 10$ nAChRs (means \pm S.E., $n=4-12$ ).

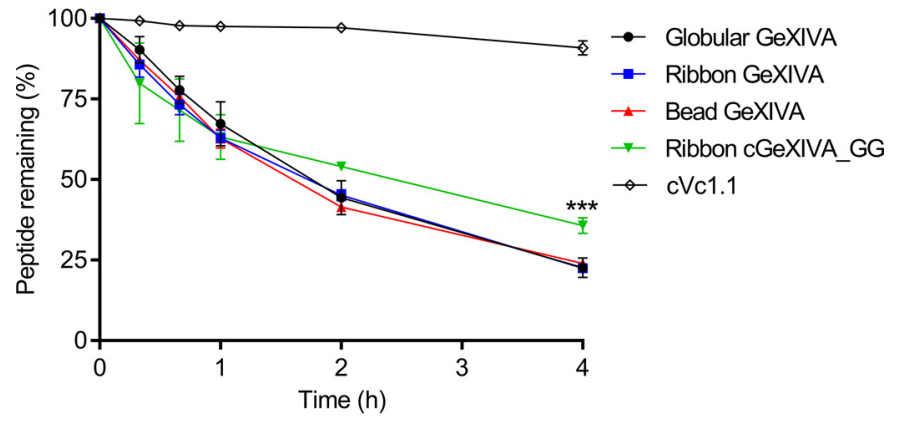

Figure 7. The stability of GeXIVA isomers, ribbon cGeXIVA_GG, and cVc1.1 (positive control) in $\mathbf{2 5 \%}$ human serum. The one-way analysis of variance/ Tukey test and was used for comparing the remaining peptides at the 4-h time point, and the data are expressed as the means \pm S.E. ${ }^{* * *}, p<0.001$. All values (except cVc1.1) were compared with that of ribbon GeXIVA.

formation of the globular isomer under similar conditions $(0.1 \mathrm{M}$ $\mathrm{NH}_{4} \mathrm{HCO}_{3}, \mathrm{pH} 8$, room temperature) $(52,53)$. A possible explanation for this difference in isomer formation is that GeXIVA displays a Cys framework XIV (C-C-C-C) with 6, 10, and 6 residues within the $\mathrm{Cys}^{\mathrm{I}}-\mathrm{Cys}^{\mathrm{II}}$, Cys ${ }^{\mathrm{II}}-\mathrm{Cys}{ }^{\mathrm{III}}$, and $\mathrm{Cys}^{\mathrm{III}}{ }_{-}$ $\mathrm{Cys}^{\mathrm{IV}}$ backbone segments, respectively, rather than the Cys framework I (CC-C-C) of most $\alpha$-conotoxins with 0,4 , and 3-7 residues between the cysteines.

The one-step oxidation of cGeXIVA_GG was notably different from that of the linear parent peptide because it resulted in the preferential formation of the ribbon isomer. The use of short cyclizing linkers has also been reported to drive oxidative folding toward the ribbon connectivity for three other conotoxins: $\alpha$-conotoxins ImI and AuIB and $\chi$-conotoxin MrIA. Like GeXIVA, these peptides have four Cys residues, with $\mathrm{Cys}^{\mathrm{I}}$ and $\mathrm{Cys}^{\mathrm{IV}}$ being no more than three residues from the $\mathrm{N}$ and $\mathrm{C}$ termini, respectively. A short cyclizing linker should maintain these two Cys residues in spatial proximity in the reduced form and favor their cross-linking by a disulfide bond during oxidation.

During the oxidative folding of ribbon GeXIVA and ribbon cGeXIVA_GG, a major intermediate was identified. For
GeXIVA, the amount of ribbon and globular isomers plateaued after 8 and $12 \mathrm{~h}$ of incubation, respectively, whereas the bead form plateaued after $20 \mathrm{~h}$. According to Wedemeyer et al. (54), the rate of formation of disulfide bonds in an unstructured chain decreases with the number of residues between the two cysteines. Because 6, 10, and 6 residues exist between successive cysteines in GeXIVA, we speculate that the major intermediate might involve a disulfide bond between Cys ${ }^{\mathrm{I}}$ and $\mathrm{Cys}^{\mathrm{II}}$ or between $\mathrm{Cys}^{\mathrm{III}}$ and $\mathrm{Cys}^{\mathrm{IV}}$ and that this intermediate subsequently translates into the bead isomer. For cGeXIVA_GG, there are only four residues between $\mathrm{Cys}^{\mathrm{I}}$ and $\mathrm{Cys}^{\mathrm{IV}}$ after backbone cyclization, which may favor the formation of either a Cys ${ }^{\mathrm{I}}-\mathrm{Cys}^{\mathrm{IV}}$ or $\mathrm{Cys}^{\mathrm{II}}-\mathrm{Cys}^{\mathrm{III}}$ disulfide bond in the intermediate, thus leading to the ribbon isomer. Interestingly, three intermediates with two disulfide connectivities appeared during the course of folding of cGeXIVA_GG. The retention times of these three intermediates were different from the three stable isomers, suggesting that the intermediates have native-like connectivities but have meta-stable conformations.

We hypothesize that the preferential formation of the ribbon isomer probably results from the destabilization of the alternative connectivities rather than through stabilization of the ribbon form (Fig. 8). Backbone cyclization of ribbon GeXIVA possibly affects the folding energy through an entropic effect, mainly impacting the unfolded state. Indeed, the linker has little interaction with the rest of the peptide in molecular models, suggesting that the termini are already maintained in proximity in the linear form, and cyclization does not result in structural perturbation to the core of the peptide. By contrast, the bead and globular isomers probably adopt a different set of conformations after being backbone cyclized because NMR characterization of these isomers indicates that the globular form is disordered, and the $\mathrm{N}$ and $\mathrm{C}$ termini of the bead isomer are uncoupled (18).

A two-step oxidation strategy is often used to oxidize conotoxins containing two disulfide bonds because the yields are 


\section{Cyclization improves selective folding of conotoxin GeXIVA}

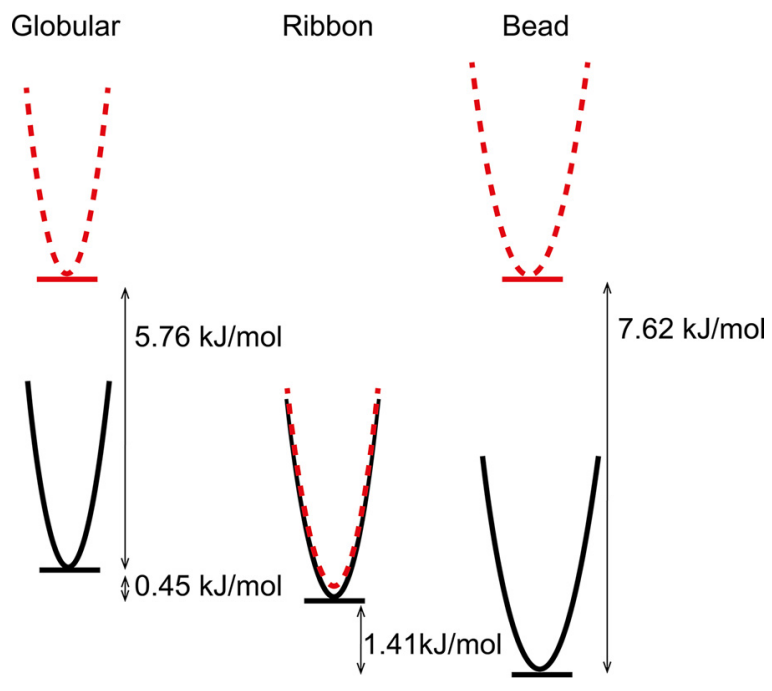

Figure 8. Schematic representation of the relative energy of the three linear isomers of GeXIVA (black lines) and their cGeXIVA_GG (dotted red lines) analogs. The energy difference between isomers of the same peptide was computed using a Boltzmann distribution of the isomers at equilibrium.

typically improved compared with undirected folding (55). However, the oxidation of GeXIVA using this strategy only produced small amounts of products, hindering high-throughput structure-activity relationship studies and therapeutic studies. The yield of folded ribbon GeXIVA calculated from the final weight of oxidized peptide divided by the weight of reduced peptide was $0.5 \%$. Using the results of Cheneval et al. (56) to extrapolate the yield for synthesis of an unprotected peptide, the yield of cyclic ribbon cGeXIVA_GG through a one-step folding method should be $8.6 \%$ using Fmoc-based solidphase peptide synthesis and considerably higher for a Bocbased approach. Additionally, the HPLC elution peaks of ribbon and bead isomers of GeXIVA overlapped, whereas the ribbon isomer of cGeXIVA_GG is distinct, and ribbon cGeXIVA_GG therefore can be produced in greater purity using one-step oxidation than the ribbon GeXIVA using the same strategy.

An alternative strategy to increase the oxidative folding yield has been used in other cases of disulfide-rich peptides, including the widely used model system bovine pancreatic trypsin inhibitor (BPTI). Undirected folding of this protein results in the formation of two main species, one being native BPTI and the other a native-like two-disulfide intermediate (57). The addition of the N-terminal pro-region increased substantially the native BPTI formation, and it was identified that a cysteine residue in this region was responsible for this increased yield (58). Tethering a cysteine residue to the $C$ terminus with a flexible linker resulted in a similar effect, indicating that this residue acts as an internal catalyst.

Backbone cyclization typically improves the stability of disulfide-rich peptides against enzymatic degradation, as demonstrated for several conotoxins, chlorotoxin, and a spider toxin $(32,35-38,59,60)$. However, it was recently reported that cyclization of $\kappa$-conotoxin PVIIA decreased its stability in human serum (61), without significantly perturbing the structure relative to the native form (62). Here, we show that the $\mathrm{IC}_{50}$ for cGeXIVA_GG inhibition of $h \alpha 9 \alpha 10 \mathrm{nAChR}(37.7 \pm 5.0 \mathrm{nM})$ is comparable with that for ribbon GeXIVA $(35.1 \pm 2.7 \mathrm{~nm})$. The stability in human serum of ribbon cGeXIVA_GG is only slightly improved compared with linear GeXIVA, suggesting that the main routes of degradation of GeXIVA are by endoproteases or side chain denaturation, which are typically less affected by backbone cyclization. A possible target for such endoproteases are the nine arginine residues in the sequence of GeXIVA (63).

Using short linkers to enhance oxidative folding and other biopharmaceutical properties of bioactive peptides has broader applications than just for toxins, with perhaps a most striking example being for insulin. Insulin is an extremely important hormone but is difficult to synthesize because of its two chain unique structure (64). In one study, the two peptide chains of human insulin were fused, increasing the production yield compared with native human proinsulin (65) while maintaining a native-like structure (66) but with an attendant loss of biological activity (67). In a later study, Hua et al. (68) used a sixresidue linker, and the resulting insulin variant maintained biological activity and structure and also had improved folding yield and stability. More recently, the nature of the linker region between the two insulin chains was further investigated, resulting in the identification of an insulin variant with the highest folding efficiency to date (64). In that study, it was shown that the linker region had a direct effect on folding yield by enhancing the formation of the native disulfide bond connectivity. The peptides in the current study have a direct analogy to singlechain insulin analogs: a suitable linker for cGeXIVA_GG led to preferential formation of the ribbon isomer and significantly improved the product yield and stability while retaining the native-like structure and biological activity. The enhanced pharmaceutical properties deriving from a suitable linker provide an opportunity to develop GeXIVA as a potential therapeutic for the treatment of neuropathic pain, a condition with a huge unmet medical need (69). Treatment of neuropathic pain is challenging, and alternative therapeutics are needed because currently available drugs such as morphine, gabapentin, or antidepressants are subject either to the development of tolerance or to significant side effects $(70,71)$.

In summary, the head-to-tail backbone cyclization via a short linker of ribbon GeXIVA had no impact on the potency of inhibition at $h \alpha 9 \alpha 10 \mathrm{nAChR}$ and a rationally designed linker favored the formation of the ribbon disulfide connectivity and improved stability in human serum. The high-yield production of ribbon cGeXIVA_GG compared with linear GeXIVA should facilitate future in vivo studies of the analgesic potential of this compound.

\section{Experimental procedures \\ Design of linkers}

Linkers were designed using molecular modeling. The structure of the ribbon isomer cyclized with linkers from one to five amino acid residues was modeled. Fifty models of the backbone cyclized ribbon GeXIVA were generated for each of the linkers using Modeler 6v13 (72), and the conservation of ribbon GeXIVA native conformation was measured by computing the 


\section{Cyclization improves selective folding of conotoxin GeXIVA}

mean $\mathrm{C} \alpha$ root-mean-square deviation between the models and the 20 lowest-energy NMR structures (18).

\section{Peptide synthesis, cyclization, oxidation, and purification of GeXIVA and variants}

The three isomers of GeXIVA and the three cyclic analogs (cGeXIVA_G, cGeXIVA_GG and cGeXIVA_GAG) were synthesized using Fmoc-based solid-phase peptide synthesis on an acid-sensitive resin 2-chlorotrityl chloride. Side chains of Cys residues were protected in pairs with orthogonal protective groups that can be removed selectively under different oxidation conditions. The acid-labile trityl group was used to protect the side chains of $\mathrm{Cys}^{2}$ and $\mathrm{Cys}^{27}$, and the acetamidomethyl group was used to protect $\mathrm{Cys}^{9}$ and $\mathrm{Cys}^{20}$ for the ribbon GeXIVA and its cyclic variants. The backbone cyclization of cyclic variants was achieved using the protocol described recently (56). Briefly, a solution of $1 \%$ TFA in dichloromethane $(\mathrm{v} / \mathrm{v})$ was used to cleave the linear precursor peptides of the cyclic variants off the resin. The side chain protected precursor peptides were dried, cyclized in $O$-(7-azabenzotriazol-1-yl)$N, N, N^{\prime}, N^{\prime}$-tetramethyluronium hexafluorophosphate $(5 \mathrm{~mm})$ and $N, N^{\prime}$-diisopropylethylamine $(10 \mathrm{~mm})$ in $N, N$-dimethylformamide for $3 \mathrm{~h}$ and lyophilized. The protecting group on side chains was removed in TFA with $2 \%$ triisopropylsilane and $2 \%$ water $(\mathrm{v} / \mathrm{v})$ for $2 \mathrm{~h}$. The three isomers of GeXIVA were cleaved and deprotected in TFA with 2\% triisopropylsilane and 2\% water $(\mathrm{v} / \mathrm{v})$ for $2 \mathrm{~h}$.

Two-step oxidative folding was used to form disulfide bonds: the first disulfide bond was formed in $0.1 \mathrm{M}$ ammonium bicarbonate $\left(\mathrm{NH}_{4} \mathrm{HCO}_{3}, \mathrm{pH} 8.3\right)$ at room temperature $\left(21-24{ }^{\circ} \mathrm{C}\right)$ for $24 \mathrm{~h}$, and the second disulfide bond was formed in $0.1 \mathrm{M}$ iodine solution for $1 \mathrm{~h}$. All peptides were purified by reversedphase (RP)-HPLC using Phenomenex C18 columns, and the purification method is 15-25\% buffer B within 40 min (increasing $1 \%$ buffer B per 4 min). Buffer $\mathrm{A}$ is $0.05 \%$ TFA in water, and buffer $\mathrm{B}$ is $0.045 \%$ TFA in $90 \%$ acetonitrile.

\section{NMR spectroscopy}

Samples of ribbon GeXIVA and its cyclic analogs were prepared by dissolving peptide $(\sim 1 \mathrm{mg})$ in $90 \% \mathrm{H}_{2} \mathrm{O}, 10 \% \mathrm{D}_{2} \mathrm{O}$ at a $\mathrm{pH}$ of $\sim 3$. The spectra were recorded on a Bruker Avance III $600 \mathrm{MHz}$ NMR spectrometer at $298 \mathrm{~K}$ and included total correlation spectroscopy (mixing time of $80 \mathrm{~ms}$ ), NOESY (mixing time of $200 \mathrm{~ms}$ ), and $\mathrm{H}-\mathrm{N}$ and $\mathrm{H}-\mathrm{C}$ heteronuclear single quantum coherence. Chemical shifts were referenced to internal 2, 2-dimethyl-2-silapentane-5-sulfonate at $0 \mathrm{ppm}$. The spectra were processed with Topspin (Bruker Biospin) and analyzed with CcpNMR analysis (version 2.4.1). Secondary $\alpha \mathrm{H}$ chemical shifts were calculated as the difference between the observed $\alpha \mathrm{H}$ chemical shifts and that of the corresponding residues in a random coil peptide (73). Structure calculations were based upon distance restraints as derived from NOESY spectra and on backbone $\varphi$ and $\psi$ dihedral angle restraints generated using TALOS + (74). A family of structures consistent with the experimental restraints was calculated using CYANA (75).

\section{Relaxation measurements}

NMR relaxation measurements were carried out as described previously (51). Briefly, ${ }^{13} \mathrm{C} \mathrm{T}_{1}$ (spin-lattice) relaxation times were measured using the Bruker pulse program hsqctletgpsi3d.2. Spectra were acquired with a spectral width of $10 \mathrm{ppm}$ over 2048 complex points in the ${ }^{1} \mathrm{H}$ dimension and $22 \mathrm{ppm}$ over 60 complex points in the ${ }^{13} \mathrm{C}$ dimension. To determine $T_{1}$ values, nine relaxation delays in the range of $0.01-1.0 \mathrm{~s}$ were used. A recycle delay of $3 \mathrm{~s}$ was used. ${ }^{13} \mathrm{C}$ NOEs were measured using the pulse program hsqcnoegpsi.2. Peak volumes were measured in CCPNMR. A recycle delay of $5 \mathrm{~s}$ was used. All experiments were carried out in triplicate. Order parameters were calculated by a model-free analysis using the same protocol and target function as described previously (51), but here the goodness-of-fit for the NOE values were given a $25 \%$ weighting compared with the $T_{1}$ values to allow for the higher uncertainty in the experimental NOE measurements.

\section{Folding assays}

Ribbon GeXIVA and cGeXIVA_GG were reduced with 10 mM dithiothreitol and isolated using RP-HPLC. Reduced peptides were dissolved in $0.1 \mathrm{M} \mathrm{NH}_{4} \mathrm{HCO}_{3}$ buffer ( $\mathrm{pH}$ 8.3) at $20 \mu \mathrm{M}$ and stirred at room temperature. An aliquot of peptide solution was removed after $0,1,4,8,12,16,20$, and $24 \mathrm{~h}$ and quenched with $2 \%$ TFA. All samples were analyzed with ultra-performance liquid chromatography using a gradient $11-18 \%$ buffer B within 28 min (increasing 1\% buffer B per $4 \mathrm{~min}$ ) in an analytical Vydac C18 column.

\section{In vitro CRNA synthesis}

Plasmid pT7TS constructs of human $\alpha 9$ and $\alpha 10 \mathrm{nAChR}$ subunits were linearized with XbaI restriction enzymes (New England Biolabs, Ipswich, MA) for in vitro cRNA transcription using T7 mMessage mMachine ${ }^{\circledR}$ transcription kits (Ambion, Foster City, CA).

\section{Oocyte preparation and microinjection}

Stage V-VI oocytes were obtained from $X$. laevis, defolliculated with $1.5 \mathrm{mg} / \mathrm{ml}$ collagenase type II (Worthington Biochemical Corp., Lakewood, NJ) at room temperature (21$23^{\circ} \mathrm{C}$ ) for $1-2 \mathrm{~h}$ in OR-2 solution containing $82.5 \mathrm{~mm} \mathrm{NaCl}, 2$ $\mathrm{mm} \mathrm{KCl,} 1 \mathrm{~mm} \mathrm{MgCl}_{2}$, and $5 \mathrm{~mm}$ HEPES, pH 7.4. The oocytes were injected with $35 \mathrm{ng}$ of cRNA for h $\alpha 9 \alpha 10 \mathrm{nAChR}$ (concentration confirmed spectrophotometrically and by gel electrophoresis) using glass pipettes pulled from glass capillaries (3-000-203 GX; Drummond Scientific Co., Broomall, PA). The oocytes were incubated at $18{ }^{\circ} \mathrm{C}$ in sterile ND96 solution composed of $96 \mathrm{~mm} \mathrm{NaCl}, 2 \mathrm{~mm} \mathrm{KCl}, 1 \mathrm{~mm} \mathrm{CaCl}_{2}, 1 \mathrm{~mm} \mathrm{MgCl}_{2}$, and $5 \mathrm{~mm}$ HEPES, pH 7.4, supplemented with 5\% fetal bovine serum, $50 \mathrm{mg} /$ liter gentamicin (Gibco) and 10,000 units/ml penicillin-streptomycin (Gibco).

\section{Oocyte two-electrode voltage clamp recording and data analysis}

Electrophysiological recordings were carried out 2-5 days after cRNA microinjection. The oocytes expressing h $\alpha 9 \alpha 10$ 


\section{Cyclization improves selective folding of conotoxin GeXIVA}

nAChRs were incubated in $100 \mu \mathrm{M}$ BAPTA-AM $\sim 3$ h before recording. Two-electrode voltage clamp recordings were performed at room temperature using a GeneClamp 500B amplifier and pClamp9 software interface (Molecular Devices, Sunnyvale, CA) at a holding potential $-80 \mathrm{mV}$. Voltage-recording and current-injecting electrodes were pulled from GC150T-7.5 borosilicate glass (Harvard Apparatus, Holliston, $\mathrm{MA}$ ) and filled with $3 \mathrm{~m} \mathrm{KCl}$, giving resistances of $0.3-1 \mathrm{M} \Omega$. The oocytes were perfused with ND115 solution containing $115 \mathrm{~mm} \mathrm{NaCl}, 2.5 \mathrm{~mm} \mathrm{KCl}, 1.8 \mathrm{~mm} \mathrm{CaCl}_{2}$, and $10 \mathrm{~mm}$ HEPES, $\mathrm{pH}$ 7.4, using a continuous Legato $270 \mathrm{push} /$ pull syringe pump perfusion system (KD Scientific, Holliston, MA) at a rate of 2 $\mathrm{ml} / \mathrm{min}$.

Initially, the oocytes were briefly washed with ND115 solution followed by three applications of ACh at half-maximal effective concentration $\left(\mathrm{EC}_{50}\right.$ ) of $6 \mu \mathrm{M}$ ACh for $\mathrm{h} \alpha 9 \alpha 10 \mathrm{nAChR}$. Washout with bath solution was done for 3 min between ACh applications. The oocytes were incubated with peptides for 5 min with the perfusion system turned off, followed by co-application of ACh and peptide with flowing bath solution. All peptide solutions were prepared in ND115 $+0.1 \%$ bovine serum albumin. Peak current amplitudes before (ACh alone) and after (ACh + peptide) peptide incubation were measured using Clampfit 10.7 software (Molecular Devices), where the ratio of ACh + peptide-evoked current amplitude to ACh aloneevoked current amplitude was used to assess the activity of the peptides at human nAChRs.

All electrophysiological data were pooled ( $n=4$ to 12$)$ and represent the means \pm S.E. Concentration-response curves were obtained using GraphPad Prism 7 nonlinear regression analysis (GraphPad Software, La Jolla, CA). The half-maximal inhibitory concentration $\left(\mathrm{IC}_{50}\right)$ was determined from the concentration-response curve and reported with error of the fit.

\section{Stability assays}

Serum stability of peptides were carried out in $25 \%$ human serum (human male AB plasma; Sigma-Aldrich) over $4 \mathrm{~h}$ using a $20 \mu \mathrm{m}$ final peptide concentration. Serum was prepared by centrifugation at $17,000 \times g$ for 15 min to remove the lipid component, and the supernatant was diluted 1 in 4 in phosphate-buffered saline and incubated at $37^{\circ} \mathrm{C}$ for $15 \mathrm{~min}$ before the assay. Each peptide was incubated in $25 \%$ human serum at $37^{\circ} \mathrm{C}$, and aliquots were taken out at time points $0,1,2,3$, and $4 \mathrm{~h}$, respectively. Serum proteins were denatured with $2 \mathrm{M}$ urea and precipitated with $20 \%$ TFA. All samples were centrifuged at $17,000 \times g$ for $10 \mathrm{~min}$, and the supernatant was analyzed by analytical RP-HPLC. Remaining peptides were quantified using peak height with absorption at $214 \mathrm{~nm}$.

Author contributions-X. W., Y.-H. H., Q. K., and D. J. C. designed the research. X. W. and Y.-H. H. conducted cyclization, NMR analysis, one-step oxidation, and stability assays. X. W., Y.-H. H., and Q. K. analyzed the results. P.J.H. conducted NMR analysis and structure calculations, and C. K. W. conducted the relaxation analysis. H.-S. T. conducted and analyzed electrophysiological results, and D. J. A. coordinated electrophysiology studies. X. W., Y.-H. H., Q. K., P. J. H., C. K. W., H.-S. T., D. J. A., and D. J. C. wrote the manuscript.
Acknowledgments-We thank Alun Jones and Eivind Undheim (Institute for Molecular Bioscience, The University of Queensland) for mass spectrometry technical support.

\section{References}

1. Thal, D. M., Sun, B., Feng, D., Nawaratne, V., Leach, K., Felder, C. C., Bures, M. G., Evans, D. A., Weis, W. I., Bachhawat, P., Kobilka, T. S., Sexton, P. M., Kobilka, B. K., and Christopoulos, A. (2016) Crystal structures of the M1 and M4 muscarinic acetylcholine receptors. Nature 531, 335-340

2. Taly, A., Corringer, P. J., Guedin, D., Lestage, P., and Changeux, J. P. (2009) Nicotinic receptors: allosteric transitions and therapeutic targets in the nervous system. Nat. Rev. Drug. Discov. 8, 733-750

3. Albuquerque, E. X., Pereira, E. F., Alkondon, M., and Rogers, S. W. (2009) Mammalian nicotinic acetylcholine receptors: from structure to function. Physiol. Rev. 89, 73-120

4. Gotti, C., Clementi, F., Fornari, A., Gaimarri, A., Guiducci, S., Manfredi, I., Moretti, M., Pedrazzi, P., Pucci, L., and Zoli, M. (2009) Structural and functional diversity of native brain neuronal nicotinic receptors. Biochem. Pharmacol. 78, 703-711

5. Terlau, H., and Olivera, B. M. (2004) Conus venoms: a rich source of novel ion channel-targeted peptides. Physiol. Rev. 84, 41-68

6. Halai, R., and Craik, D. J. (2009) Conotoxins: natural product drug leads. Nat. Prod. Rep. 26, 526-536

7. Kaas, Q., Yu, R., Jin, A. H., Dutertre, S., and Craik, D. J. (2012) ConoServer: updated content, knowledge, and discovery tools in the conopeptide database. Nucleic Acids Res. 40, D325-D330

8. Lewis, R. J., Dutertre, S., Vetter, I., and Christie, M. J. (2012) Conus venom peptide pharmacology. Pharmacol. Rev. 64, 259-298

9. Akondi, K. B., Muttenthaler, M., Dutertre, S., Kaas, Q., Craik, D. J., Lewis, R. J., and Alewood, P. F. (2014) Discovery, synthesis, and structure-activity relationships of conotoxins. Chem. Rev. 114, 5815-5847

10. Miljanich, G. P. (2004) Ziconotide: neuronal calcium channel blocker for treating severe chronic pain. Curr. Med. Chem. 11, 3029-3040

11. Jain, K. K. (2000) An evaluation of intrathecal ziconotide for the treatment of chronic pain. Expert. Opin. Investig. Drugs 9, 2403-2410

12. Gorson, J., and Holford, M. (2016) Small packages, big returns: uncovering the venom diversity of small invertebrate conoidean snails. Integr. Comp. Biol. 56, 962-972

13. Mohammadi, S. A., and Christie, M. J. (2015) Conotoxin interactions with $\alpha 9 \alpha 10$-nAChRs: Is the $\alpha 9 \alpha 10$-nicotinic acetylcholine receptor an important therapeutic target for pain management? Toxins 7, 3916-3932

14. Callaghan, B., and Adams, D. J. (2010) Analgesic $\alpha$-conotoxins Vc1.1 and RgIA inhibit N-type calcium channels in sensory neurons of $\alpha 9$ nicotinic receptor knockout mice. Channels (Austin) 4, 51-54

15. Klimis, H., Adams, D. J., Callaghan, B., Nevin, S., Alewood, P. F., Vaughan, C. W., Mozar, C. A., and Christie, M. J. (2011) A novel mechanism of inhibition of high-voltage activated calcium channels by $\alpha$-conotoxins contributes to relief of nerve injury-induced neuropathic pain. Pain 152, $259-266$

16. Nevin, S. T., Clark, R. J., Klimis, H., Christie, M. J., Craik, D. J., and Adams, D. J. (2007) Are $\alpha 9 \alpha 10$ nicotinic acetylcholine receptors a pain target for $\alpha$-conotoxins? Mol. Pharmacol. 72, 1406-1410

17. Callaghan, B., Haythornthwaite, A., Berecki, G., Clark, R. J., Craik, D. J., and Adams, D. J. (2008) Analgesic $\alpha$-conotoxins Vc1.1 and Rg1A inhibit $\mathrm{N}$-type calcium channels in rat sensory neurons via $\mathrm{GABA}_{\mathrm{B}}$ receptor activation. J. Neurosci. 28, 10943-10951

18. Luo, S., Zhangsun, D., Harvey, P. J., Kaas, Q., Wu, Y., Zhu, X., Hu, Y., Li, X., Tsetlin, V. I., Christensen, S., Romero, H. K., McIntyre, M., Dowell, C., Baxter, J. C., Elmslie, K. S., et al. (2015) Cloning, synthesis, and characterization of $\alpha \mathrm{O}$-conotoxin GeXIVA, a potent $\alpha 9 \alpha 10$ nicotinic acetylcholine receptor antagonist. Proc. Natl. Acad. Sci. U.S.A. 112, E4026-E4035

19. Yu, R., Kompella, S. N., Adams, D. J., Craik, D. J., and Kaas, Q. (2013) Determination of the $\alpha$-conotoxin Vc1.1 binding site on the $\alpha 9 \alpha 10$ nicotinic acetylcholine receptor. J. Med. Chem. 56, 3557-3567 


\section{Cyclization improves selective folding of conotoxin GeXIVA}

20. Ellison, M., Haberlandt, C., Gomez-Casati, M. E., Watkins, M., Elgoyhen, A. B., McIntosh, J. M., and Olivera, B. M. (2006) $\alpha$-RgIA: a novel conotoxin that specifically and potently blocks the $\alpha 9 \alpha 10$ nAChR. Biochemistry 45, $1511-1517$

21. Li, X., Hu, Y., Wu, Y., Huang, Y., Yu, S., Ding, Q., Zhangsun, D., and Luo, S. (2016) Anti-hypersensitive effect of intramuscular administration of $\alpha$ O-conotoxin GeXIVA [1,2] and GeXIVA [1,4] in rats of neuropathic pain. Prog. Neuropsychopharmacol. Biol. Psychiatry 66, 112-119

22. Craik, D. J., Fairlie, D. P., Liras, S., and Price, D. (2013) The future of peptide-based drugs. Chem. Biol. Drug. Des. 81, 136-147

23. King, G. F. (2011) Venoms as a platform for human drugs: translating toxins into therapeutics. Expert. Opin. Biol. Ther. 11, 1469-1484.

24. Frokjaer, S., and Otzen, D. E. (2005) Protein drug stability: a formulation challenge. Nat. Rev. Drug. Discov. 4, 298-306

25. Craik, D. J., Daly, N. L., Bond, T., and Waine, C. (1999) Plant cyclotides: a unique family of cyclic and knotted proteins that defines the cyclic cystine knot structural motif. J. Mol. Biol. 294, 1327-1336

26. Conibear, A. C., and Craik, D. J. (2014) The chemistry and biology of theta defensins. Angew. Chem. Int. Ed. Engl. 53, 10612-10623

27. Klaenhammer, T. R. (1993) Genetics of bacteriocins produced by lactic acid bacteria. FEMS Microbiol. Rev. 12, 39-85

28. Hemu, X., Taichi, M., Qiu, Y., Liu, D. X., and Tam, J. P. (2013) Biomimetic synthesis of cyclic peptides using novel thioester surrogates. Biopolymers 100, 492-501

29. Akcan, M., and Craik, D. (2015) J Engineering venom peptides to improve their stability and bioavailability. In Venoms to Drugs: Venom as a Source for the Development of Human Therapeutics (King, G. F., ed) pp. 275-289, RSC Publishing, Cambridge, UK

30. Craik, D. J. (2006) Seamless proteins tie up their loose ends. Science 311, 1563-1564

31. Clark, R. J., Akcan, M., Kaas, Q., Daly, N. L., and Craik, D. J. (2012) Cyclization of conotoxins to improve their biopharmaceutical properties. Toxicon 59, $446-455$

32. Wu, X., Huang, Y. H., Kaas, Q., and Craik, D. J. (2016) Cyclisation of disulfide-rich conotoxins in drug design applications. Eur. J. Org. Chem. 2016, 3462-3472, 10.1002/ejoc.201600402

33. Clark, R. J., Jensen, J., Nevin, S. T., Callaghan, B. P., Adams, D. J., and Craik, D. J. (2010) The engineering of an orally active conotoxin for the treatment of neuropathic pain. Angew. Chem. Int. Ed. Engl. 49, 6545-6548

34. Armishaw, C. J., Dutton, J. L., Craik, D. J., and Alewood, P. F. (2010) Establishing regiocontrol of disulfide bond isomers of $\alpha$-conotoxin ImI via the synthesis of N-to-C cyclic analogs. Biopolymers 94, 307-313

35. Armishaw, C. J., Jensen, A. A., Balle, L. D., Scott, K. C., Sørensen, L., and Strømgaard, K. (2011) Improving the stability of $\alpha$-conotoxin AuIB through N-to-C cyclization: the effect of linker length on stability and activity at nicotinic acetylcholine receptors. Antioxid. Redox. Signal. 14, $65-76$

36. Lovelace, E. S., Gunasekera, S., Alvarmo, C., Clark, R. J., Nevin, S. T., Grishin, A. A., Adams, D. J., Craik, D. J., and Daly, N. L. (2011) Stabilization of $\alpha$-conotoxin AuIB: influences of disulfide connectivity and backbone cyclization. Antioxid. Redox. Signal. 14, 87-95

37. Dekan, Z., Wang, C.-I., Andrews, R. K., Lewis, R. J., and Alewood, P. F. (2012) Conotoxin engineering: dual pharmacophoric noradrenaline transport inhibitor/integrin binding peptide with improved stability. Org. Biomol. Chem. 10, 5791-5794

38. Lovelace, E. S., Armishaw, C. J., Colgrave, M. L., Wahlstrom, M. E., Alewood, P. F., Daly, N. L., and Craik, D. J. (2006) Cyclic MrIA: a stable and potent cyclic conotoxin with a novel topological fold that targets the norepinephrine transporter. J. Med. Chem. 49, 6561-6568

39. Elgoyhen, A. B., Vetter, D. E., Katz, E., Rothlin, C. V., Heinemann, S. F., and Boulter, J. (2001) $\alpha 10$ : a determinant of nicotinic cholinergic receptor function in mammalian vestibular and cochlear mechanosensory hair cells. Proc. Natl. Acad. Sci. U.S.A. 98, 3501-3506

40. Koval, L., Lykhmus, O., Zhmak, M., Khruschov, A., Tsetlin, V., Magrini, E., Viola, A., Chernyavsky, A., Qian, J., Grando, S., Komisarenko, S., and Skok, M. (2011) Differential involvement of $\alpha 4 \beta 2, \alpha 7$ and $\alpha 9 \alpha 10$ nicotinic acetylcholine receptors in B lymphocyte activation in vitro. Int. J. Biochem. Cell Biol. 43, 516-524
41. Peng, H., Ferris, R. L., Matthews, T., Hiel, H., Lopez-Albaitero, A., and Lustig, L. R. (2004) Characterization of the human nicotinic acetylcholine receptor subunit $\alpha 9$ (CHRNA9) and $\alpha 10$ (CHRNA10) in lymphocytes. Life. Sci. 76, 263-280

42. Satkunanathan, N., Livett, B., Gayler, K., Sandall, D., Down, J., and Khalil, Z. (2005) $\alpha$-Conotoxin Vc1.1 alleviates neuropathic pain and accelerates functional recovery of injured neurones. Brain. Res. 1059, 149-158

43. Wu, C. H., Lee, C. H., and Ho, Y. S. (2011) Nicotinic acetylcholine receptor-based blockade: applications of molecular targets for cancer therapy. Clin. Cancer Res. 17, 3533-3541

44. Wu, R. J., Wang, L., and Xiang, H. (2015) The structural features of $\alpha$-conotoxin specifically target different isoforms of nicotinic acetylcholine receptors. Curr. Top. Med. Chem. 16, 156-169

45. Xu, S., Zhang, T., Kompella, S. N., Yan, M., Lu, A., Wang, Y., Shao, X., Chi, C., Adams, D. J., Ding, J., and Wang, C. (2015) Conotoxin $\alpha$ D-GeXXA utilizes a novel strategy to antagonize nicotinic acetylcholine receptors. Sci. Rep. 5, 14261

46. Luo, S., Christensen, S., Zhangsun, D., Wu, Y., Hu, Y., Zhu, X., Chhabra, S., Norton, R. S., and McIntosh, J. M. (2013) A novel inhibitor of $\alpha 9 \alpha 10$ nicotinic acetylcholine receptors from Conus vexillum delineates a new conotoxin superfamily. PLoS One 8, e54648

47. Halai, R., Callaghan, B., Daly, N. L., Clark, R. J., Adams, D. J., and Craik, D. J. (2011) Effects of cyclization on stability, structure, and activity of $\alpha$-conotoxin RgIA at the $\alpha 9 \alpha 10$ nicotinic acetylcholine receptor and $\mathrm{GABA}_{\mathrm{B}}$ receptor. J. Med. Chem. 54, 6984-6992

48. Clark, R. J., and Craik, D. J. (2012) Engineering cyclic peptide toxins. Methods Enzymol. 503, 57-74

49. Clark, R. J., Fischer, H., Dempster, L., Daly, N. L., Rosengren, K. J., Nevin, S. T., Meunier, F. A., Adams, D. J., and Craik, D. J. (2005) Engineering stable peptide toxins by means of backbone cyclization: stabilization of the $\alpha$-conotoxin MII. Proc. Natl. Acad. Sci. U.S.A. 102, 13767-13772

50. Carstens, B. B., Swedberg, J., Berecki, G., Adams, D. J., Craik, D. J., and Clark, R. J. (2016) Effects of linker sequence modifications on the structure, stability and biological activity of a cyclic $\alpha$-conotoxin. Biopolymers 106, $864-875$

51. Wang, C. K., Swedberg, J. E., Northfield, S. E., and Craik, D. J. (2015) Effects of cyclization on peptide backbone dynamics. J. Phys. Chem. B 119, $15821-15830$

52. Wu, X., Wu, Y., Zhu, F., Yang, Q., Wu, Q., Zhangsun, D., and Luo, S. (2013) Optimal cleavage and oxidative folding of $\alpha$-conotoxin TxIB as a therapeutic candidate peptide. Mar. Drugs. 11, 3537-3553

53. Gyanda, R., Banerjee, J., Chang, Y.-P., Phillips, A. M., Toll, L., and Armishaw, C. J. (2013) Oxidative folding and preparation of $\alpha$-conotoxins for use in high-throughput structure-activity relationship studies. J. Pept. Sci. $19,16-24$

54. Wedemeyer, W. J., Xu, X., Welker, E., and Scheraga, H. A. (2002) Conformational propensities of protein folding intermediates: distribution of species in the $1 \mathrm{~S}, 2 \mathrm{~S}$, and $3 \mathrm{~S}$ ensembles of the [C40A,C95A] mutant of bovine pancreatic ribonuclease A. Biochemistry 41, 1483-1491

55. Bulaj, G., and Olivera, B. M. (2008) Folding of conotoxins: formation of the native disulfide bridges during chemical synthesis and biosynthesis of Conus peptides. Antioxid. Redox. Signal. 10, 141-155

56. Cheneval, O., Schroeder, C. I., Durek, T., Walsh, P., Huang, Y. H., Liras, S., Price, D. A., and Craik, D. J. (2014) Fmoc-based synthesis of disulfide-rich cyclic peptides. J. Org. Chem. 79, $5538-5544$

57. States, D. J., Dobson, C. M., Karplus, M., and Creighton, T. (1984) A new two-disulphide intermediate in the refolding of reduced bovine pancreatic trypsin inhibitor. J. Mol. Biol. 174, 411-418

58. Weissman, J. S., and Kim, P. S. (1992) The pro region of BPTI facilitates folding. Cell 71, 841-851

59. Akcan, M., Stroud, M. R., Hansen, S. J., Clark, R. J., Daly, N. L., Craik, D. J., and Olson, J. M. (2011) Chemical re-engineering of chlorotoxin improves bioconjugation properties for tumor imaging and targeted therapy. J. Med. Chem. 54, 782-787

60. Jensen, J. E., Mobli, M., Brust, A., Alewood, P. F., King, G. F., and Rash, L. D. (2012) Cyclisation increases the stability of the sea anemone peptide APETx2 but decreases its activity at acid-sensing ion channel 3. Mar. Drugs 10, 1511-1527 


\section{Cyclization improves selective folding of conotoxin GeXIVA}

61. Kwon, S., Bosmans, F., Kaas, Q., Cheneval, O., Conibear, A. C., Rosengren, K. J., Wang, C. K., Schroeder, C. I., and Craik, D. J. (2016) Efficient enzymatic cyclization of an inhibitory cystine knot-containing peptide. Biotechnol. Bioeng. 113, 2202-2212

62. Scanlon, M. J., Naranjo, D., Thomas, L., Alewood, P. F., Lewis, R. J., and Craik, D. J. (1997) Solution structure and proposed binding mechanism of a novel potassium channel toxin $\kappa$-conotoxin PVIIA. Structure 5, 1585-1597

63. Thomas, G. (2002) Furin at the cutting edge: from protein traffic to embryogenesis and disease. Nat. Rev. Mol. Cell Biol. 3, 753-766

64. Zaykov, A. N., Mayer, J. P., Gelfanov, V. M., and DiMarchi, R. D. (2014) Chemical synthesis of insulin analogs through a novel precursor. ACS Chem. Biol. 9, 683-691

65. Markussen, J. (1985) Comparative reduction/oxidation studies with single chain des-(B30) insulin and porcine proinsulin. Int. J. Pept. Protein Res. 25, 431-434

66. Derewenda, U., Derewenda, Z., Dodson, E. J., Dodson, G. G., Bing, X., and Markussen, J. (1991) X-ray analysis of the single chain B29-A1 peptidelinked insulin molecule: a completely inactive analogue. J. Mol. Biol. 220, 425-433

67. Markussen, J., Jørgensen, K. H., Sørensen, A. R., and Thim, L. (1985) Single chain des-(B30) insulin: intramolecular crosslinking of insulin by trypsin catalyzed transpeptidation. Int. J. Pept. Protein Res. 26, 70-77

68. Hua, Q. X., Nakagawa, S. H., Jia, W., Huang, K., Phillips, N. B., Hu, S. Q., and Weiss, M. A. (2008) Design of an active ultrastable single-chain insulin analog: synthesis, structure, and therapeutic implications. J. Biol. Chem. 283, 14703-14716
69. Colloca, L., Ludman, T., Bouhassira, D., Baron, R., Dickenson, A. H., Yarnitsky, D., Freeman, R., Truini, A., Attal, N., Finnerup, N. B., Eccleston, C., Kalso, E., Bennett, D. L., Dworkin, R. H., and Raja, S. N. (2017) Neuropathic pain. Nat. Rev. Dis. Primers. 3, 17002

70. Dworkin, R. H., O'Connor, A. B., Backonja, M., Farrar, J. T., Finnerup, N. B., Jensen, T. S., Kalso, E. A., Loeser, J. D., Miaskowski, C., Nurmikko, T. J., Portenoy, R. K., Rice, A. S., Stacey, B. R., Treede, R. D., Turk, D. C., et al. (2007) Pharmacologic management of neuropathic pain: evidencebased recommendations. Pain 132, 237-251

71. Cruccu, G. (2007) Treatment of painful neuropathy. Curr. Opin. Neurol. 20, $531-535$

72. Sali, A., and Blundell, T. L. (1993) Comparative protein modelling by satisfaction of spatial restraints. J. Mol. Biol. 234, 779-815

73. Wishart, D. S., Sykes, B. D., and Richards, F. M. (1992) The chemical shift index: a fast and simple method for the assignment of protein secondary structure through NMR spectroscopy. Biochemistry 31, 1647-1651

74. Shen, Y., Delaglio, F., Cornilescu, G., and Bax, A. (2009) TALOS+: a hybrid method for predicting protein backbone torsion angles from NMR chemical shifts. J. Biomol. NMR. 44, 213-223

75. Ikeya, T., Terauchi, T., Güntert, P., and Kainosho, M. (2006) Evaluation of stereo-array isotope labeling (SAIL) patterns for automated structural analysis of proteins with CYANA. Magn. Reson. Chem. 44, S152-S157

76. Chen, V. B., Arendall, W. B., 3rd, Headd, J. J., Keedy, D. A., Immormino, R. M., Kapral, G. J., Murray, L. W., Richardson, J. S., and Richardson, D. C. (2010) MolProbity: all-atom structure validation for macromolecular crystallography. Acta Crystallogr. D Biol. Crystallogr. 66, 12-21 